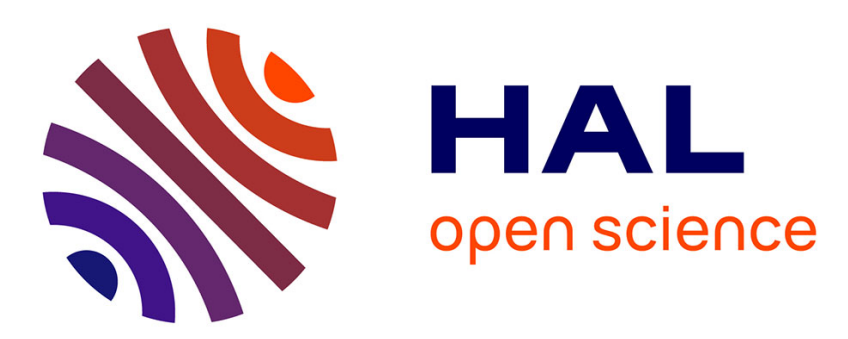

\title{
Observations of thermal tides in the middle atmosphere of Mars by the SPICAM instrument
}

Paul Withers, Robert Pratt, Jean-Loup Bertaux, Franck Montmessin

\section{To cite this version:}

Paul Withers, Robert Pratt, Jean-Loup Bertaux, Franck Montmessin. Observations of thermal tides in the middle atmosphere of Mars by the SPICAM instrument. Journal of Geophysical Research. Planets, 2011, 116 (E11), pp.E11005. 10.1029/2011JE003847 . hal-00642614

\section{HAL Id: hal-00642614 https://hal.science/hal-00642614}

Submitted on 12 Nov 2016

HAL is a multi-disciplinary open access archive for the deposit and dissemination of scientific research documents, whether they are published or not. The documents may come from teaching and research institutions in France or abroad, or from public or private research centers.
L'archive ouverte pluridisciplinaire HAL, est destinée au dépôt et à la diffusion de documents scientifiques de niveau recherche, publiés ou non, émanant des établissements d'enseignement et de recherche français ou étrangers, des laboratoires publics ou privés. 


\title{
Observations of thermal tides in the middle atmosphere of Mars by the SPICAM instrument
}

\author{
Paul Withers, ${ }^{1}$ R. Pratt, ${ }^{1}$ J.-L. Bertaux, ${ }^{2}$ and F. Montmessin ${ }^{2}$ \\ Received 15 April 2011; revised 31 August 2011; accepted 11 September 2011; published 18 November 2011.
}

[1] We use vertical profiles of Martian atmospheric density, pressure, and temperature from the Mars Express SPICAM UV spectrometer to study thermal tides in the poorly studied middle atmosphere region at $70-120 \mathrm{~km}$. Here we show that nonmigrating tides cause zonal pressure variations of tens of percent and zonal temperature variations on the order of $10 \mathrm{~K}$ in these observations. Wave- 2 and wave- 3 components are dominant, consistent with previous work at lower and higher altitudes and with theoretical predictions. Normalized pressure amplitudes tend to increase with altitude for the cases and altitudes studied here. Phases of the pressure variations vary little with altitude, indicating long vertical wavelengths for the underlying tidal modes. We derive theoretical relationships between zonal variations in temperature and in pressure and find that they are generally satisfied. Failure of these relationships can be used to infer the presence of multiple tidal modes contributing to a single observed wave component. The wave- 2 component is dominated by the diurnal Kelvin wave 1 (DK1) above about $80 \mathrm{~km}$ but contains multiple tidal modes below this altitude. In one unusual instance, $40^{\circ} \mathrm{S}-30^{\circ} \mathrm{S}$, $\mathrm{Ls}=150^{\circ}-180^{\circ}$, and local time of $22-24 \mathrm{~h}$, the usually strong wave- 2 component is extremely weak. The wave- 3 component is always dominated by a single tidal mode, which for tropical and extratropical latitudes we identify as the diurnal Kelvin wave 2 (DK2).

Citation: Withers, P., R. Pratt, J.-L. Bertaux, and F. Montmessin (2011), Observations of thermal tides in the middle atmosphere of Mars by the SPICAM instrument, J. Geophys. Res., 116, E11005, doi:10.1029/2011JE003847.

\section{Introduction}

[2] Global-scale oscillations in atmospheric state variables, such as density, pressure, and temperature, that are driven by periodic solar forcing are known as thermal tides [Chapman and Lindzen, 1970; Forbes, 1995]. Thermal tides are particularly prominent on Mars due to its rapid rotation rate and the low atmospheric density at its surface [Zurek, 1976; Wilson and Hamilton, 1996; Zurek et al., 1992].

[3] Tides are important to atmospheric science and related disciplines because they can (1) be responsible for a significant fraction of an atmosphere's variability, (2) strongly influence variations in surface pressure, (3) affect zonal-mean winds and thermal structure in regions where they dissipate, and (4) affect atmospheric stability. They also possess intrinsic scientific value as a basic phenomenon in geophysical fluid dynamics.

[4] In addition, tides are particularly important for understanding the Martian atmosphere because (1) they are predicted to be prominent contributors to the dynamics of the Martian atmosphere [Forbes et al., 2002]; (2) they affect the transport of suspended dust, water, and other atmospheric

\footnotetext{
${ }^{1}$ Astronomy Department, Boston University, Boston, Massachusetts, USA.

${ }^{2}$ Service d'Aéronomie du CNRS, Verrières-le-Buisson, France.

Copyright 2011 by the American Geophysical Union. 0148-0227/11/2011JE003847
}

constituents that in turn affect the chemistry, dynamics, and thermal structure of the atmosphere [Zurek et al., 1992]; and (3) they are predicted to affect the zonal mean structure and dynamics of the middle and upper atmospheric regions [Moudden and Forbes, 2008a].

[5] The $50-150 \mathrm{~km}$ region of the atmosphere is an important part of the Mars system [e.g., Barth et al., 1992; Zurek, 1992; Zurek et al., 1992; Magalhães et al., 1999]. The nominal thermal structure at these altitudes is dominated by the cold mesopause at $90-120 \mathrm{~km}$ and the transition to the isothermal exosphere around $180 \mathrm{~km}$ [e.g., Bougher et al., 2002; Forget et al., 2009; McDunn et al., 2010]. Large lapse rates occur above the mesopause, since temperatures can increase from 100 to $120 \mathrm{~K}$ at the mesopause to 160 $180 \mathrm{~K}$ several scale heights higher up. The mesopause lies between the lower atmosphere, which is heated by visible solar radiation and infrared emissions from suspended dust and $\mathrm{CO}_{2}$ gas, and the upper atmosphere, which is heated by solar UV/EUV radiation. The global circulation patterns between $50 \mathrm{~km}$ and $150 \mathrm{~km}$ have not been directly observed. Strong global-scale thermal tides are present, as are smallerscale gravity waves [Forbes et al., 2002; Withers et al., 2003; Tolson et al., 2005; Creasey et al., 2006]. These vertically propagating disturbances interact with each other and with the mean circulation, transferring energy and momentum as they ascend [Forbes et al., 2002]. The 50-150 km region of the atmosphere contains the homopause $(\sim 120 \mathrm{~km})$ and a significant portion of the ionosphere (100-200 km); it also 
plays a major role in controlling the transport of light species up into the exosphere $(>180 \mathrm{~km})$ [Chamberlain and Hunten, 1987]. Some of the major questions related to this part of the atmosphere are as follows. How variable are the mesopause's altitude and temperature and what causes those variations? What is the global circulation? How does the middle and upper atmosphere respond to dust storms in the lower atmosphere? How are waves/tides in the lower and upper regions of the atmosphere related?

[6] Several previous investigations have discussed observations of thermal tides below $50 \mathrm{~km}$ [e.g., Zurek, 1976; Wilson and Hamilton, 1996; Zurek et al., 1992; Banfield et al., 2000] and above $100 \mathrm{~km}$ [e.g., Forbes and Hagan, 2000; Wilson, 2002; Withers et al., 2003; Angelats $i$ Coll et al., 2004] in the Martian atmosphere. Few have discussed observations at intermediate altitudes [Cahoy et al., 2006; Forget et al., 2009; Lee et al., 2009; Heavens et al., 2010], although thermal tides are anticipated to be important in the middle region of the atmosphere. Atmospheric properties in this atmospheric region are difficult to measure because densities are too small to be accessible by typical infrared remote sensing techniques, yet too large for safe operation of a deep-dipping orbital spacecraft, which precludes in situ measurements by accelerometers or other instruments. Hence the middle atmosphere had not been comprehensively observed prior to the Mars Express (MEX) and Mars Reconnaissance Orbiter (MRO) missions.

[7] The objectives of this work are to use observations from the Spectroscopy for the Investigation of the Characteristics of the Atmosphere of Mars (SPICAM) UV spectrometer instrument on MEX [Bertaux et al., 2004, 2006; Quémerais et al., 2006] to characterize the most significant tidal components in the middle atmosphere and to relate tides in the middle atmosphere to tides at other altitudes. A particular goal is to determine whether a given tidal component comprises one or more underlying tidal modes. We use individual stellar occultation profiles of atmospheric density, pressure, and temperature to construct two dimensional cross sections of pressure and temperature as functions of longitude and altitude at fixed season, latitude, and local time. Tides can cause these atmospheric state variables to vary with longitude and for the amplitudes and phases of these zonal variations to depend on altitude. Section 2 introduces thermal tides, section 3 summarizes relevant previous work on Martian tides, and section 4 introduces the SPICAM data set. Sections 5 and 6 describe zonal pressure and temperature variations in SPICAM profiles. Section 7 summarizes our conclusions.

\section{Introduction to Atmospheric Thermal Tides}

[8] Here we summarize the key characteristics of thermal tides that are relevant for this work. Further details are provided in Appendix A for interested readers. An atmospheric tide has a true zonal wave number, $s$, a frequency $n \Omega$ from which a period can be found, and a zonal wave number in a fixed local solar time reference frame of $m$, where $s$ is an integer, $n$ is a nonnegative integer, $\Omega$ is the planetary rotation rate, and $m$ is a nonnegative integer. In idealized tidal theory, the variation of each $(s, n)$ tidal component with latitude can be represented as the sum of a series of Hough functions, where each Hough function is identified by a label $i$
[Chapman and Lindzen, 1970; Forbes, 1995]. An $(s, n)$ tidal component is often dominated by the one $(s, n, i)$ Hough mode whose meridional dependence approximates that of solar heating (symmetric about the equator, no nodes close to the equator, and maximized at the equator rather than the poles). Also, each Hough function has a specific dependence on altitude, either exponential decay (evanescent) or harmonic oscillation (propagating), that is characterized by a single vertical wavelength. Many different tidal modes can cause the same variations with longitude in a fixed local solar time reference frame, which describes the SPICAM observations used here. One of the goals of this work is to use theoretical expectations of how the properties of a tidal mode vary with altitude and latitude to infer which tidal mode (or modes) is (or are) responsible for the zonal variations apparent in SPICAM observations. The dependence of tidal properties on local solar time will also be used to discriminate between diurnal and semidiurnal modes. The value of identifying the physical process responsible for producing a particular observed atmospheric feature is that it then becomes possible to make predictions about atmospheric behavior at unobserved conditions and to firmly relate these observations to other data sets.

\section{Previous Work on Martian Tides}

[9] Tides may vary with season, so we introduce the symbol Ls, the areocentric longitude of the Sun, to describe Martian seasons [Kieffer et al., 1992; Zurek et al., 1992]. Ls, which is $0^{\circ}$ at the northern spring equinox, varies between $0^{\circ}$ and $360^{\circ}$ during a Mars Year. Tides in the Martian atmosphere have been previously studied using observations and simulations. Observations have shown that thermal tides are significant at the surface, in the lower atmosphere, and in the upper atmosphere. The most comprehensive analyses of tidal effects in surface pressure data have used data from the longlived Viking 1 and 2 landers [Seiff, 1976; Hess et al., 1977]. Tidal variations in temperatures in the lowest few scale heights of the atmosphere have been studied in data sets from the Mariner 9 infrared interferometer spectrometer (IRIS), Viking Orbiter infrared thermal mapper (IRTM), Mars Global Surveyor (MGS) Thermal Emission Spectrometer (TES), and Radio Science (RS) instruments on MGS and MEX [Hanel et al., 1972; Martin et al., 1979; Hinson et al., 1999; Smith et al., 2001; Pätzold et al., 2004]. Tidal variations above the lowest few scale heights of the atmosphere have been studied in data sets from the MRO Mars Climate Sounder (MCS), MGS RS, and MGS, Odyssey (ODY) and MRO accelerometer (ACC) instruments [McCleese et al., 2007; Hinson et al., 1999; Keating et al., 1998; Tolson et al., 2005; Withers, 2006; Tolson et al., 2008]. Pertinent numerical simulations have also been performed by a range of authors.

[10] The most well-studied Martian tidal modes are migrating tidal modes, stationary tidal modes, and three other nonmigrating tidal modes $(n=1, s=-1 ; n=1, s=-2$; and $n=2, s=-1)$. Since migrating tides do not cause zonal variations in a fixed local time reference frame, we do not discuss them further in this study. The dominant Hough modes for these three nonmigrating tidal modes are the diurnal Kelvin wave known as DK1, the diurnal Kelvin wave known as DK2, and the semidiurnal Kelvin wave known as 
SK1, respectively, where the numeral following the DK/SK prefix is $|s|$ [Chapman and Lindzen, 1970; Andrews et al., 1987; Forbes, 1995]. In a fixed local time reference frame, DK1 causes wave-2 zonal variations and DK2 and SK1 cause wave- 3 zonal variations. All three of these have been observed throughout the Martian atmosphere. We now summarize previous work on these three nonmigrating tidal modes and stationary waves to provide context for subsequent interpretation of SPICAM observations.

\subsection{DK1}

[11] The $n=1, s=-1$ nonmigrating tidal mode that is dominated by DK1 is present in Viking surface pressure data during dusty conditions [Zurek and Leovy, 1981; Zurek, 1988; Wilson and Hamilton, 1996; Bridger and Murphy, 1998]. From a comprehensive tidal analysis of TES lower atmospheric temperatures over a range of seasons, Banfield et al. [2000] and Banfield et al. [2003] found that this mode is concentrated in the tropics, varies little with season, and has an amplitude of $1-2 \mathrm{~K}$ in the lowest four scale heights. From analysis of MGS RS profiles and numerical simulations, Hinson et al. [2008] found that its near-surface amplitude at $\mathrm{Ls}=35^{\circ}-70^{\circ}$ in the tropics is on the order of $200 \mathrm{~m}$ in geopotential height or about $2 \%$ in density or pressure. From analysis of MGS thermospheric densities at Ls $\sim 90^{\circ}$, Withers et al. [2003] found a wave-2 component, which they interpreted as DK1, with a density amplitude of $20 \%$ in the tropics and midlatitudes and a diurnal period at midlatitudes. The numerical simulations of Bougher et al. [2004] at Ls $\sim 90^{\circ}$ predicted that DK1's thermospheric density amplitude is $15 \%$ and that it is confined to the tropics, the numerical simulations of Angelats $i$ Coll et al. [2004] at Ls $65^{\circ}$ found density amplitudes of $20 \%$ in the tropics, and the numerical simulations of Wilson [2002] at Ls $=80^{\circ}$ found density amplitudes of $40 \%$ in the tropics. The numerical simulations of Forbes and Miyahara [2006] at Ls $=30^{\circ}-80^{\circ}$ found density amplitudes of $20 \%$ at $125 \mathrm{~km}$ in the tropics that decreased toward the poles more rapidly than amplitudes did in observed MGS thermospheric densities. They also reproduced the observed phases successfully.

\subsection{DK2}

[12] The $n=1, s=-2$ nonmigrating tidal mode that is dominated by DK2 was found by Banfield et al. [2000] and Banfield et al. [2003] to be concentrated in the tropics, to vary little with season, and to have an amplitude of $\sim 1 \mathrm{~K}$ in the lowest four scale heights. This tidal mode was not detected in the lower atmosphere by Hinson et al. [2008]. Bougher et al. [2004] $\left(\mathrm{Ls} \sim 90^{\circ}\right)$ found that DK2 is strong in the northern hemisphere only. Angelats $i$ Coll et al. [2004] (Ls $\sim 65^{\circ}$ ) found amplitudes of $16 \%$ in the tropics. Wilson [2002] $\left(\mathrm{Ls}=80^{\circ}\right)$ found DK2 amplitudes that are about half those of DK1. Forbes and Miyahara [2006] (Ls $=30^{\circ}$ $80^{\circ}$ ) found amplitudes of $20 \%$ at $125 \mathrm{~km}$ in the tropics. Simulated amplitudes decreased toward both poles, but amplitudes observed in MGS thermospheric densities decreased less rapidly than simulated in the northern hemisphere. Observed phases varied much more with longitude than simulated phases did.

\subsection{SK1}

[13] Bougher et al. [2001], who compared radio occultation and accelerometer data sets, deduced that the wave- 3 component at thermospheric altitudes, $60^{\circ} \mathrm{N}-65^{\circ} \mathrm{N}$ and $\mathrm{Ls}=$ $30^{\circ}-75^{\circ}$, which has density or pressure amplitudes of $15 \%$ $20 \%$, is produced by the $n=2, s=-1$ nonmigrating tidal mode that is dominated by SK1. From analysis of MGS thermospheric densities at Ls $\sim 90^{\circ}$, Withers et al. [2003] found a wave- 3 component with an amplitude of $20 \%$ in the tropics and midlatitudes and a semidiurnal period at midlatitudes, which they interpreted as SK1. Using local time variations in MGS RS ionospheric electron density profiles, Cahoy et al. [2007] found that wave-3 structure is dominated by SK 1 at $85^{\circ} \mathrm{N}$ and $\mathrm{Ls} \sim 150^{\circ}$. Bougher et al. [2004] (Ls $\left.\sim 90^{\circ}\right)$ and Angelats $i$ Coll et al. [2004] $(\mathrm{Ls}=$ $65^{\circ}$ ) found that SK1 is strong at high northern latitudes only. Wilson [2002] $\left(\mathrm{Ls}=80^{\circ}\right)$ found SK1 amplitudes comparable to DK2. This mode was not detected in the lower atmosphere by Banfield et al. [2000], Banfield et al. [2003], or Hinson et al. [2008].

\subsection{Stationary Waves}

[14] Stationary waves that can create the wave-2 and wave-3 components of zonal variations are generally predicted to be weaker than these nonmigrating tidal modes at thermospheric altitudes [Angelats $i$ Coll et al., 2004]. Withers et al. [2003] had difficulty interpreting the wave-1 component of observed thermospheric zonal variations in terms of specific tidal modes and the theoretical simulations of Angelats $i$ Coll et al. [2004] indicated that a stationary wave may contribute to this component. Wave-wave interactions may play a role in producing appreciable stationary wave amplitudes at thermospheric altitudes, since their ability to propagate from the surface to the thermosphere is extremely limited [Hollingsworth and Barnes, 1996; Angelats $i$ Coll et al., 2004]. Moudden and Forbes [2008b], who also numerically simulated the wave- 1 component of thermospheric density variations, found that the diurnal zonally symmetric tidal mode $(n=1, s=0)$ may be significant.

\section{SPICAM Atmospheric Profiles}

[15] Recent measurements of hundreds of vertical profiles of atmospheric density, pressure, and temperature between $\sim 20 \mathrm{~km}$ and $\sim 120 \mathrm{~km}$ by the SPICAM instrument on ESA's MEX spacecraft are well-suited for studies of thermal tides in the middle atmosphere [Bertaux et al., 2004, 2006; Quémerais et al., 2006]. SPICAM is a UV spectrometer that can record a star's spectrum during a stellar occultation [Bertaux et al., 2004, 2006]. Attenuation of starlight along the raypath is controlled by the altitude-dependent slant column density of atmospheric constituents and the wavelengthdependent absorption cross sections of these constituents. A vertical profile of $\mathrm{CO}_{2}$ number density has been determined from each stellar occultation observed by SPICAM and vertical profiles of mass density, pressure, and temperature have been determined from each profile of $\mathrm{CO}_{2}$ number density [Quémerais et al., 2006]. Although formal results have been obtained down to $\sim 20 \mathrm{~km}$, the effects of dust make the derived atmospheric densities and temperatures unreliable below $50 \mathrm{~km}$ and $70 \mathrm{~km}$, respectively [Quémerais et al., 2006; Forget et al., 2009]. Forget et al. [2009] and McDunn et al. 

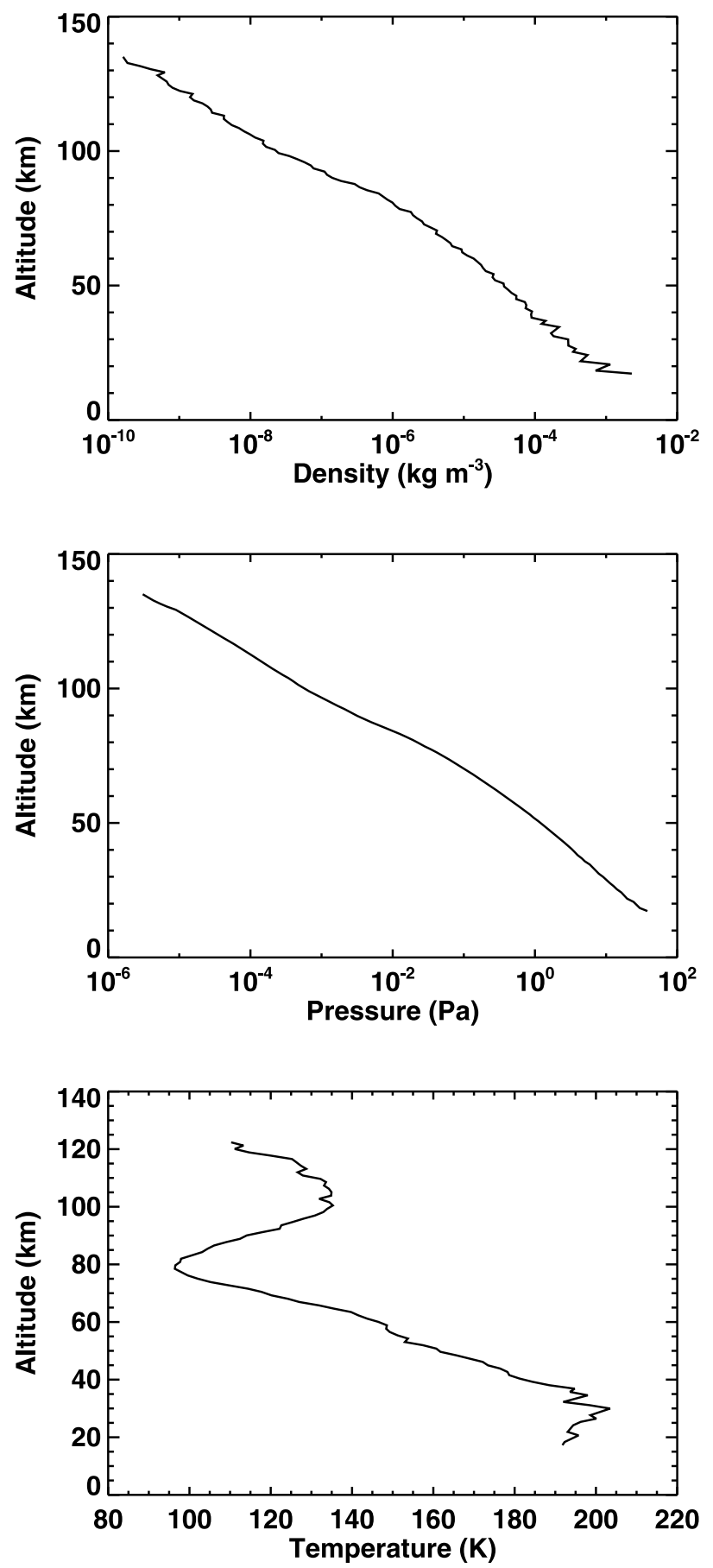

Figure 1. Atmospheric density, pressure, and temperature profiles obtained from SPICAM stellar occultation 0906 at $42.44^{\circ} \mathrm{S}, 58.09^{\circ} \mathrm{E}, \mathrm{LST}=3.4 \mathrm{~h}$, and $\mathrm{Ls}=95.77^{\circ}$ of Mars Year 27 (3 October 2004).

[2010] have analyzed the SPICAM profiles to study the thermal structure and dynamics of the middle atmosphere of Mars, as well as the processes that control them.

[16] Atmospheric profiles have been obtained for a range of latitudes, longitudes, local solar times (LSTs), seasons (Ls), and Mars Years (MYs), where our usage of Mars Years follows the convention introduced by Clancy et al. [2000]. A typical atmospheric profile is shown in Figure 1. Typical vertical resolution in the raw data is about $1 \mathrm{~km}$, although some of the profiles used in this work have been smoothed to a resolution of 2-3 $\mathrm{km}$ to reduce noise. Typical uncertainties in the derived atmospheric properties are approximately $10 \%$ in density and pressure, and $10 \mathrm{~K}$ in temperature [Forget et al., 2009]. In this paper, we use the 491 profiles that are publicly available from http://bdap.ipsl.jussieu.fr/. Most were obtained between 22 February 2004 (orbit 134, Ls = $353.4^{\circ}$, MY 26) and 12 March 2006 (orbit 2779, Ls $=23.3^{\circ}$, MY 28), with one earlier profile on 14 January 2004 (orbit $\left.17, \mathrm{Ls}=332.8^{\circ}, \mathrm{MY} 26\right)$ and one later profile on 11 April 2006 (orbit $2888, \mathrm{Ls}=37.6^{\circ}$, MY 28). The latitude, LST, and Ls coverage of these profiles is shown in Figure 2 of Forget et al. [2009] and Figure 1 of McDunn et al. [2010].

[17] We have identified four cases in which multiple SPICAM profiles were obtained within narrow ranges of Ls, LST and latitude, yet sampled all longitudes (Table 1). Thermal tides, if present, will produce zonal variations in each of these cases.

\section{Variations in Pressure With Longitude in SPICAM Observations}

[18] Figure 2 uses data at $110 \mathrm{~km}$ altitude from Case $\mathrm{C}$ to illustrate that substantial variations in pressure with longitude at fixed altitude are apparent in SPICAM observations. These variations are caused by nonmigrating thermal tides. Figure 2 also displays a harmonic fit to the data (Tables 2-3). The wave- 2 component is strongest and the wave- 3 component is also significant, but the wave- 1 component is weak.

[19] The fitting procedures used were outlined by Withers et al. [2003] and Withers [2003]. The fitted harmonics were truncated at wave- 3 because the amplitudes of higher order terms, when included, were rarely significant. We adopted the convention that the phase of a given harmonic is the longitude of its first peak east of $0^{\circ}$ longitude. Thus the phase of the wave- $n$ harmonic must lie between $0^{\circ} \mathrm{E}$ and $360^{\circ} \mathrm{E} / n$. Individual measurement uncertainties were not used in the fitting procedure, as discussed by Withers et al. [2003]. Day-to-day variability in the atmosphere, not the characteristics of the SPICAM instrument, is the main reason why repeated measurements at a given longitude are not identical.

[20] The effects of thermal tides vary with season, latitude, and LST, as illustrated for the four cases in Figures 2-5. Fitted harmonic amplitudes and phases are reported in Tables 2-3. Zonal variations in pressure can be observed over a broad altitude range (about $70 \mathrm{~km}$ to $120 \mathrm{~km}$ ) using SPICAM data, as shown for case A in Figures 6-7. Despite nonmigrating tides being produced at low altitudes by atmosphere-surface interactions, zonal pressure variations

Table 1. Cases Where Multiple SPICAM Profiles Were Obtained Within Narrow Range of Ls, LST, and Latitude ${ }^{\mathrm{a}}$

\begin{tabular}{llrrr}
\hline Case & $N$ & \multicolumn{1}{c}{ Latitude } & \multicolumn{1}{c}{ Ls } & \multicolumn{1}{c}{ LST (h) } \\
\hline A & 53 & $60^{\circ} \mathrm{S}-30^{\circ} \mathrm{S}$ & $90^{\circ}-120^{\circ}$ & $1.0-5.0$ \\
$\mathrm{~B}$ & 29 & $15^{\circ} \mathrm{N}-45^{\circ} \mathrm{N}$ & $240^{\circ}-270^{\circ}$ & $0.8-3.5$ \\
$\mathrm{C}$ & 34 & $20^{\circ} \mathrm{S}-10^{\circ} \mathrm{S}$ & $90^{\circ}-120^{\circ}$ & $2.6-4.8$ \\
$\mathrm{D}$ & 27 & $40^{\circ} \mathrm{S}-30^{\circ} \mathrm{S}$ & $150^{\circ}-180^{\circ}$ & $22.0-24.0$ \\
\hline
\end{tabular}

${ }^{\mathrm{a}} N$ is the number of profiles in each case. 


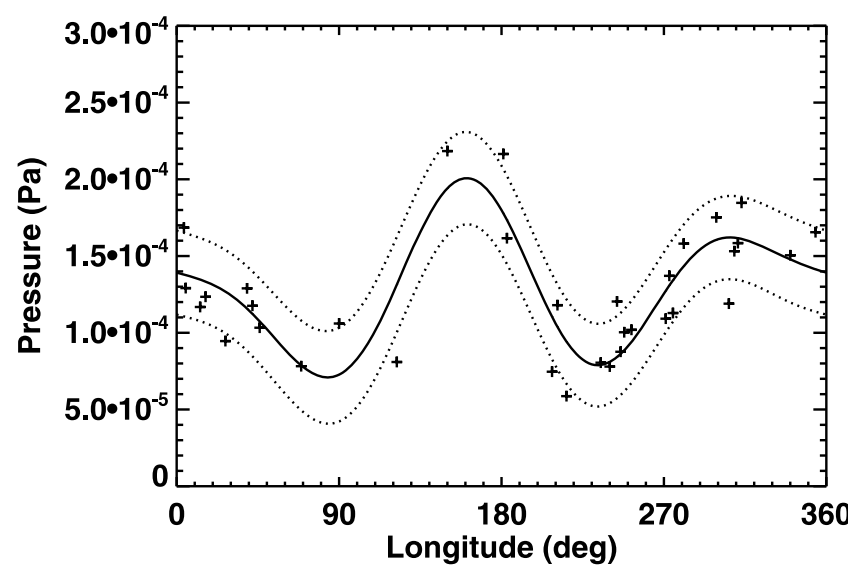

Figure 2. Crosses show pressure measurements at $110 \mathrm{~km}$ for case $\mathrm{C}$. The solid line is a harmonic fit to the data and the two dotted lines indicate the $1 \sigma$ uncertainty envelope about the fit.

are not detectable at $50-70 \mathrm{~km}$. We conclude that tidal amplitudes at these altitudes are too small for tidal effects to stand out above other, more stochastic atmospheric variations and the uncertainties in individual measurements. Although tidal effects are strong above $120 \mathrm{~km}$, SPICAM profiles do not extend to higher altitudes.

\subsection{Dominant Components}

[21] The wave-2 and wave- 3 components of zonal pressure variations in Figures 3-5 are generally stronger than the wave-1 component, consistent with previous work at thermospheric altitudes and theoretical predictions concerning the importance of DK1, DK2, and SK1 (section 3). Between $70 \mathrm{~km}$ and $110 \mathrm{~km}$ altitude, the fitted amplitude of the wave- 1 component only exceeds 0.2 in case B, whose seasonal extent differs greatly from those of the other cases (Table 1). This is also the only northern hemisphere case. However, the wave-1 component in density observations at $130 \mathrm{~km}, 10^{\circ} \mathrm{N}-50^{\circ} \mathrm{N}$, and $\mathrm{Ls} \approx 50^{\circ}$ by the MGS accelerometer instrument had a relative amplitude of less than 0.1 [Withers et al., 2003]. It is therefore probable that the root cause of the strong wave-1 component in case B lies with this case's season, not its latitude. The season of case B, Ls = $240^{\circ}-270^{\circ}$, is a much dustier one than Ls $\approx 50^{\circ}$ [Smith, 2004] and atmospheric tides are sensitive to the thermal effects of atmospheric dust.

[22] The amplitude of the wave-2 component is unusually small, $0.013 \pm 0.047$ at $110 \mathrm{~km}$, in case D. This component's fitted amplitude exceeds 0.2 at $110 \mathrm{~km}$ in cases $\mathrm{A}-\mathrm{C}$ and is also large in most MGS accelerometer density

Table 2. Fitted Amplitudes and $1 \sigma$ Uncertainties for Pressure Measurements at $110 \mathrm{~km}$ in Cases $\mathrm{A}-\mathrm{D}^{\mathrm{a}}$

\begin{tabular}{ccccc}
\hline Case & $p_{0}(\mathrm{~Pa})$ & $w_{p 1}$ & $w_{p 2}$ & $w_{p 3}$ \\
\hline $\mathrm{A}$ & $1.46 \mathrm{E}-04 \pm 8.28 \mathrm{E}-06$ & $0.05 \pm 0.08$ & $0.31 \pm 0.09$ & $0.14 \pm 0.08$ \\
$\mathrm{~B}$ & $1.07 \mathrm{E}-03 \pm 7.34 \mathrm{E}-05$ & $0.23 \pm 0.10$ & $0.21 \pm 0.10$ & $0.35 \pm 0.09$ \\
$\mathrm{C}$ & $1.29 \mathrm{E}-04 \pm 5.10 \mathrm{E}-06$ & $0.08 \pm 0.06$ & $0.35 \pm 0.06$ & $0.18 \pm 0.05$ \\
$\mathrm{D}$ & $1.12 \mathrm{E}-03 \pm 4.18 \mathrm{E}-05$ & $0.12 \pm 0.05$ & $0.01 \pm 0.05$ & $0.15 \pm 0.05$ \\
\hline
\end{tabular}

${ }^{\mathrm{a}}$ The term $p_{0}$ is the fitted zonally uniform pressure (Pascals) and $w_{p n}$ is the normalized amplitude of the wave- $n$ component (dimensionless).
Table 3. Fitted Phases and $1 \sigma$ Uncertainties for Pressure Measurements at $110 \mathrm{~km}$ in Cases $\mathrm{A}-\mathrm{D}^{\mathrm{a}}$

\begin{tabular}{lcrr}
\hline Case & \multicolumn{1}{c}{$\phi_{p 1}$} & \multicolumn{1}{c}{$\phi_{p 2}$} & \multicolumn{1}{c}{$\phi_{p 3}$} \\
\hline A & $319.2 \pm 90.5$ & $155.7 \pm 7.5$ & $38.8 \pm 10.6$ \\
B & $147.6 \pm 22.4$ & $118.6 \pm 12.4$ & $24.5 \pm 4.9$ \\
C & $230.2 \pm 40.9$ & $155.9 \pm 4.4$ & $42.2 \pm 5.4$ \\
D & $143.1 \pm 21.9$ & $24.2 \pm 107.1$ & $109.3 \pm 6.1$ \\
\hline
\end{tabular}

${ }^{\mathrm{a}}$ The term $\phi_{p n}$ is the phase of the wave- $n$ component (degrees).

observations at $130 \mathrm{~km}$ [Withers et al., 2003]. The unprecedented weakness of the wave- 2 component extends over all altitudes in this case. It may well be connected with the significant and unusual dust storm that occurred around Ls $=$ $130^{\circ}$ [Smith et al., 2006; Forget et al., 2009]. Since thermal tides are significantly weaker in case $\mathrm{D}$ than in cases $\mathrm{A}-\mathrm{C}$, the remainder of this work focuses on cases $\mathrm{A}-\mathrm{C}$.

\subsection{Dependence of Phase on Altitude}

[23] Figures 8-10 show how the amplitudes and phases of the three components of zonal pressure variations depend on altitude for cases $\mathrm{A}-\mathrm{C}$. The first impression is that these phases vary little with altitude, yet upon further inspection, it is clear that the phases of the wave- 2 and wave- 3 components are not completely insensitive to altitude. This has implications for the vertical propagation of the underlying tidal modes responsible for these zonal pressure variations. Patterns in the phase of the wave-1 component, which often has large uncertainties, are unclear.

\subsubsection{Wave-2}

[24] In cases $\mathrm{A}-\mathrm{C}$, the wave-2 phase varies little with altitude both below and above a narrow transition region centered around $90 \mathrm{~km}$ altitude. Yet in each of these three cases, the wave- 2 phase shifts eastward by about $20^{\circ}$ over a vertical distance of $5-10 \mathrm{~km}$ as the altitude increases past about $90 \mathrm{~km}$. In each of these three cases, this slight phase shift is accompanied by a change in the amplitude of the wave-2 component. Below the transition region, this amplitude is relatively constant at about 0.1 . Above the transition region, this amplitude is much larger than 0.1 and tends to increase with increasing altitude. This is interpreted in section 5.5.2 as suggesting that dominance of the wave-2

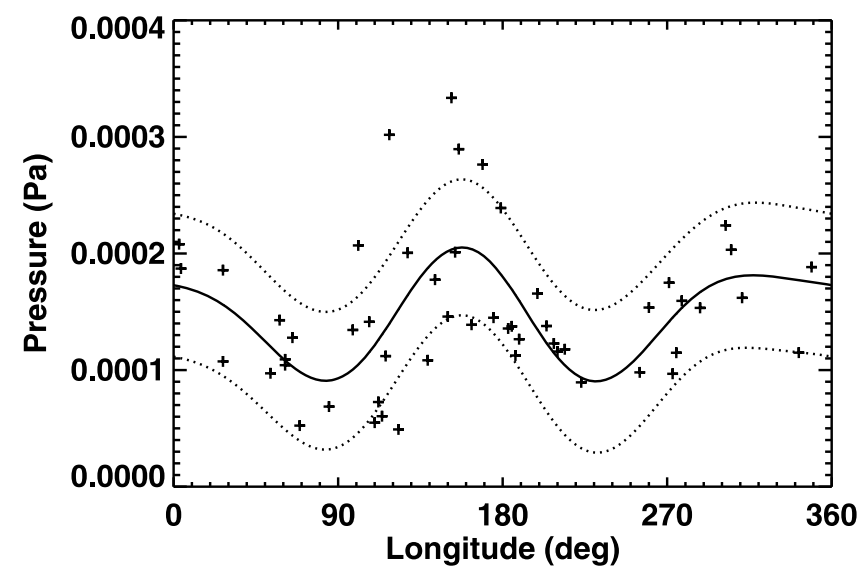

Figure 3. As Figure 2, but for case A. 


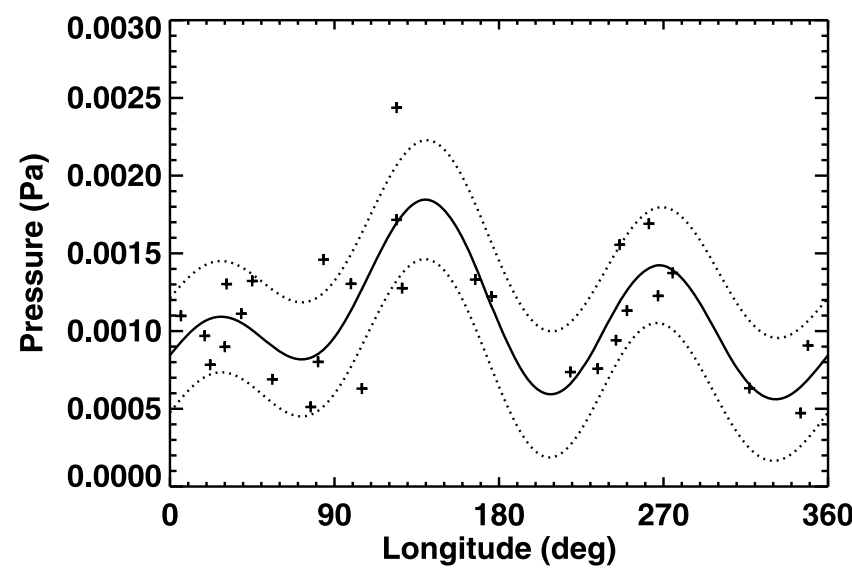

Figure 4. As Figure 2, but for case B.

component by DK1 begins at this transition altitude, not below.

\subsubsection{Wave-3}

[25] Changes in the phase of the wave- 3 component are more subtle. Broadly speaking, the wave- 3 phase moves westward with increasing altitude until a transition altitude, then reverses direction and moves eastward with increasing altitude. This transition altitude is also approximately $90 \mathrm{~km}$, although it is somewhat lower for Case $\mathrm{C}$ than for Cases $\mathrm{A}$ and B. Unlike the wave- 2 component, there is not a strong association between these transition altitudes and increases in the amplitude of this component.

\subsection{Diurnal or Semidiurnal Tidal Modes?}

[26] If the wave- $n$ component of observed zonal pressure variations is caused by a diurnal tidal mode, then the phase of this component will change by half of its full range $\left(360^{\circ} \mathrm{E} / n\right)$ if the local time changes by half a sol. If it is caused by a semidiurnal tidal mode, then the phase will not change.

\subsubsection{Wave-2}

[27] The phase of the wave-2 component is almost identical for cases $\mathrm{A}$ and $\mathrm{C}$, which have similar seasonal and local time coverage. Case A covers the southern extratropics and case $C$ covers the southern tropics. MGS accelerometerderived density observations at the same latitudes, a slightly earlier season, and local times about half a sol later have a wave- 2 phase around $70^{\circ}$ at $130 \mathrm{~km}$ [Withers et al., 2003], which differs by $85^{\circ} \pm 5^{\circ}$ from the characteristic $155^{\circ} \pm 5^{\circ}$ phase of the wave- 2 component in cases $\mathrm{A}$ and $\mathrm{C}$ at $110 \mathrm{~km}$. This is consistent with the expected phase separation of $90^{\circ}$ for a diurnal tidal mode, which agrees with the earlier conclusions of many investigators that the wave- 2 component of zonal density/pressure variations is dominated by the DK1 tidal mode. Dominance by a meridionally broad tidal mode like DK1 would also tend to lead to similarities in the phase over a wide range of latitudes, as seen in cases $\mathrm{A}$ and $\mathrm{C}$.

\subsubsection{Wave-3}

[28] The phase of the wave- 3 component is also similar for cases $\mathrm{A}$ and $\mathrm{C}$. MGS accelerometer-derived density observations at the same latitudes, a slightly earlier season, and local times about half a sol later have a wave- 3 phase around $100^{\circ}$ [Withers et al., 2003], which differs by $60^{\circ} \pm 8^{\circ}$ from the characteristic $40^{\circ} \pm 8^{\circ}$ phase of the wave- 3 component in cases $\mathrm{A}$ and $\mathrm{C}$ at $110 \mathrm{~km}$. This is the expected phase separation of $60^{\circ}$ for a diurnal tidal mode such as DK2. By contrast, the data analysis efforts of Bougher et al. [2001], Withers et al. [2003], and Cahoy et al. [2007] found that SK1, not DK2, dominated the wave-3 component of their observations (section 3). The simulations of Wilson [2002] at Ls $=80^{\circ}$, although noting the sensitivity of their results to uncertain damping processes, found the SK1 tidal mode should be stronger than the DK2 tidal mode at high northern latitudes, but not at other latitudes, which may account for the difference between the results of this work $\left(60^{\circ} \mathrm{S}-10^{\circ} \mathrm{S}\right)$ and those of Bougher et al. $[2001]\left(60^{\circ} \mathrm{N}-65^{\circ} \mathrm{N}\right)$ and Cahoy et al. [2007] $\left(85^{\circ} \mathrm{N}\right)$. If SK1 is also dominant at high southern latitudes, then this would account for the difference between the results of this work $\left(60^{\circ} \mathrm{S}-10^{\circ} \mathrm{S}\right)$ and those of Withers et al. [2003] $\left(70^{\circ} \mathrm{S}-50^{\circ} \mathrm{S}\right)$. The simplest possible explanation for all these observations at Ls $\sim 90^{\circ}$ is that DK2 is dominant in the tropics, up to about $50^{\circ}$ or $60^{\circ}$ latitude, and SK1 is dominant at more poleward latitudes.

\subsection{Values of Phases}

[29] If the phases of components of zonal density/pressure variations vary little with altitude between $70 \mathrm{~km}$ and $160 \mathrm{~km}$, then the question that arises is are the values of these phases primarily determined by processes in the lower atmosphere or by the zonal inhomogeneities at the Martian surface that create the nonmigrating tidal modes? Either options has interesting consequences if the dominant tidal mode can be determined. If the first option is true, then the phase of a particular component provides information about conditions in the lower atmosphere. If the second option is true, then the phase of a particular component is relatively insensitive to season and latitude, which would enable more efficient aerobraking operations and would help scientists deal better with longitudinal variations in a range of thermospheric and ionospheric data sets.

[30] The phases of the wave-2 component in cases A-C of this work and the nightside case reported in Table 3 of Withers et al. [2003], all of which have local times of a few hours past midnight, are around $120^{\circ}-150^{\circ}$, rather than distributed across the full range of $180^{\circ}$. Hinson et al.

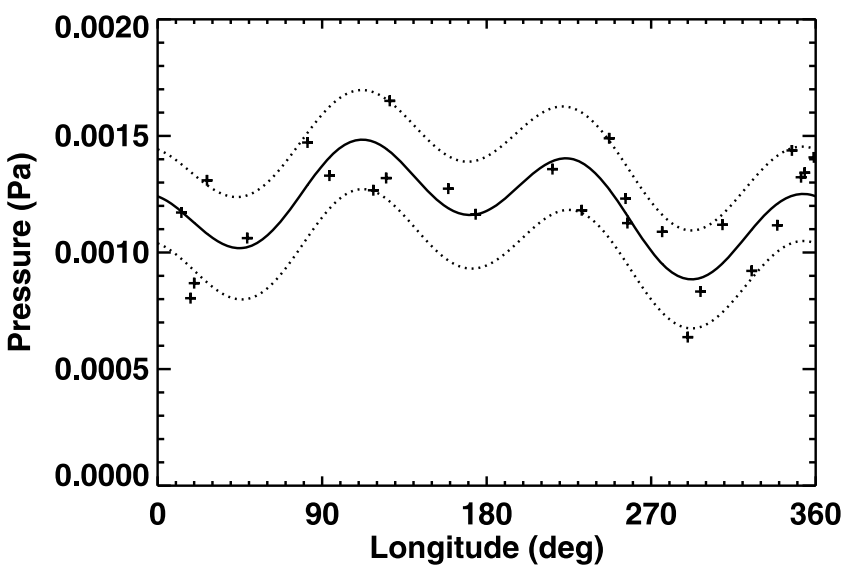

Figure 5. As Figure 2, but for case D. 


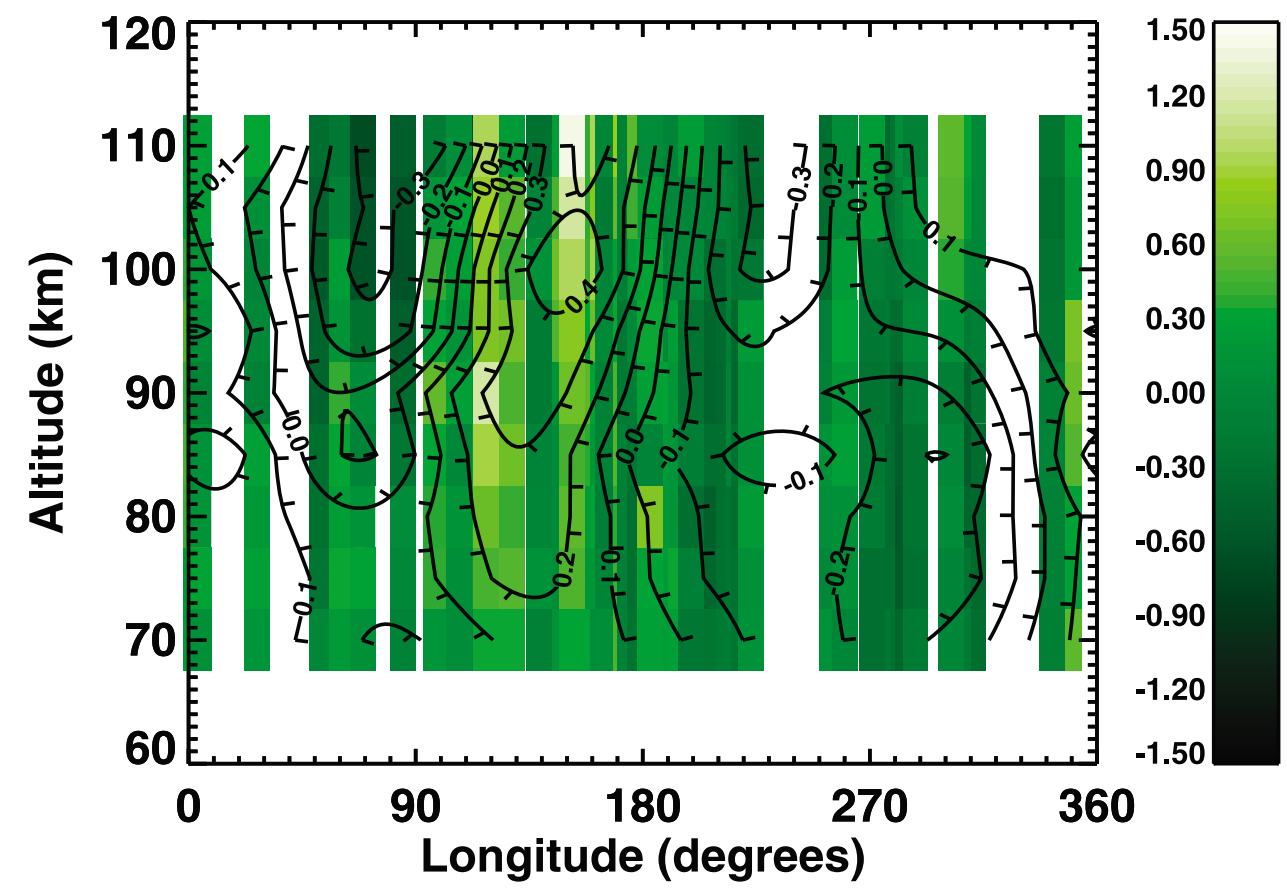

Figure 6. Normalized pressure variations with longitude $\left(0^{\circ} \mathrm{E}-360^{\circ} \mathrm{E}\right)$ and altitude $(60-120 \mathrm{~km})$ for case A. Pressure measurements for case A were extracted at $5 \mathrm{~km}$ intervals, then fitted by a series of harmonic functions. The labeled contours show how the difference between the fitted pressure and the zonally uniform pressure term, normalized by the zonally uniform pressure term, varies with longitude and altitude. The colored blocks show how the difference between the measured pressure and the zonally uniform pressure term, normalized by the zonally uniform pressure term, varies with longitude and altitude. The vertical extent of each block, $5 \mathrm{~km}$, indicates the vertical spacing of the pressure measurements used. The horizontal extent of each block has no significance.

[2008] reported a phase of $150^{\circ}-160^{\circ}$ at $0-40 \mathrm{~km}$ altitude for a wave- 2 component dominated by DK1 at $\mathrm{Ls}=35^{\circ}$ $70^{\circ}, 35^{\circ} \mathrm{N}$ and LST $=4.2 \mathrm{~h}$. The phase of the DK1 tidal mode barely changes between the surface and the thermosphere, confirming that it is fixed by surface characteristics throughout the atmosphere. This is consistent with simulations [e.g., Wilson, 2000]. It is also noteworthy that the wave- 3 phases in cases $\mathrm{A}-\mathrm{C}$ of this work and the nightside case of Withers et al. [2003] are around $0^{\circ}-40^{\circ}$, rather than distributed across the full range of $120^{\circ}$.

\subsection{Dissipation}

[31] The rate of change of amplitude of a particular component with altitude is determined by two factors. Conservation of energy in an idealized, dissipationless atmosphere should keep the product of atmospheric density and the square of a tidal mode's relative amplitude the same at all altitudes [Chapman and Lindzen, 1970; Forbes, 1995]. However, dissipation in a real atmosphere reduces tidal amplitudes below this limit. We define $L$, a dissipative lengthscale, as follows:

$$
A=A_{0} \exp \left(\frac{z}{2 H}\right) \exp \left(\frac{-z}{L}\right)
$$

where $A$ is the amplitude, $A_{0}$ is a reference amplitude, $z$ is altitude, and $H$ is the scale height. If $L$ is positive, then a larger value of $L$ corresponds to weaker dissipation. If $L$ is negative, then the amplitude of this component is increasing

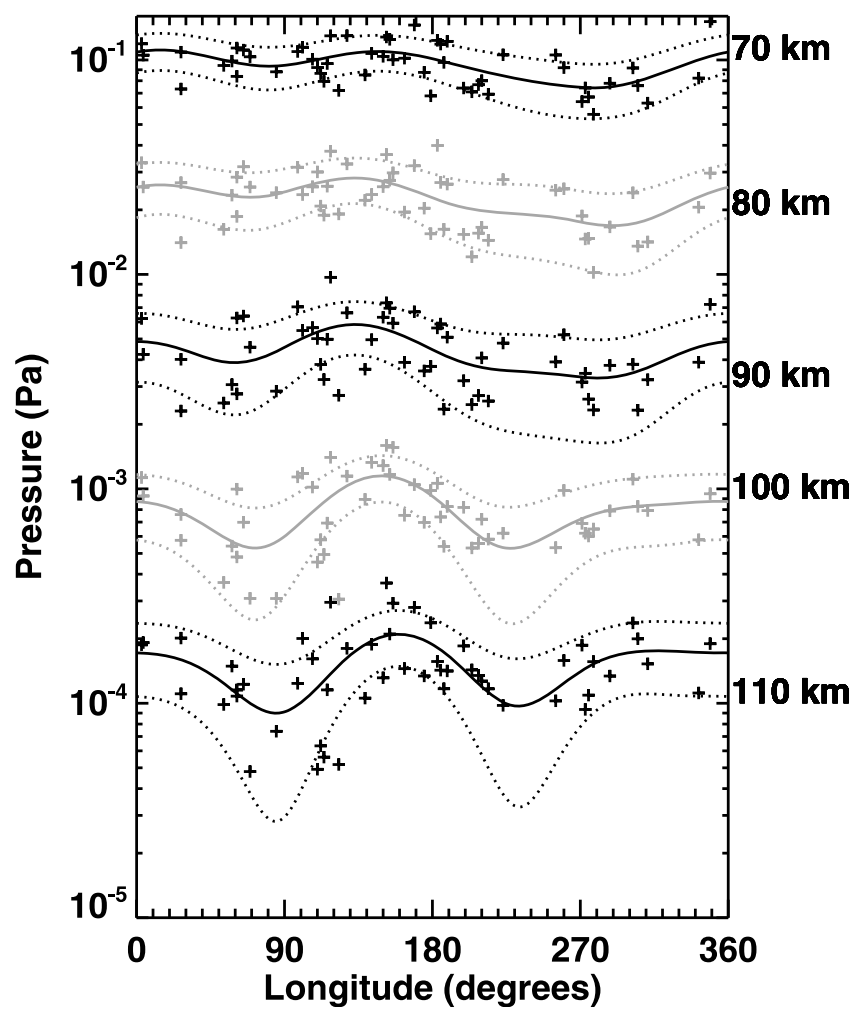

Figure 7. Pressure variations with longitude and altitude for case A. 

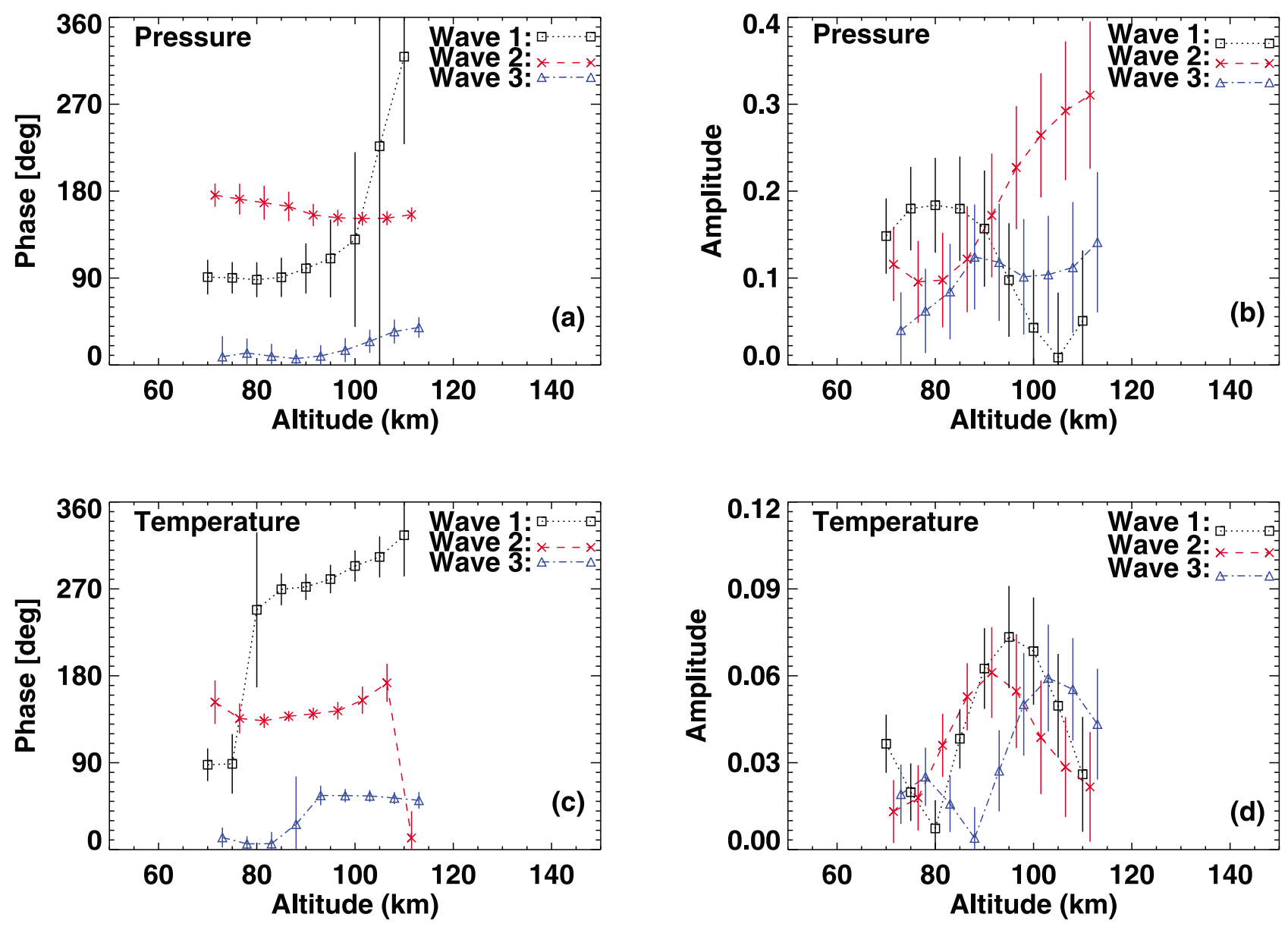

Figure 8. (a) Fitted phases and $1 \sigma$ uncertainties for pressure measurements at $5 \mathrm{~km}$ intervals for case A. Black squares identify wave-1, red crosses identify wave-2, and blue triangles identify wave- 3 . To minimize confusion caused by overlapping symbols, wave- 2 and wave- 3 symbols are plotted several $\mathrm{km}$ above their actual altitudes. (b) The corresponding fitted normalized amplitudes and $1 \sigma$ uncertainties using the same symbols as Figure 8a. (c and d) The same as Figures $8 \mathrm{a}$ and $8 \mathrm{~b}$, but for temperature measurements.

faster than the theoretical limit for a tidal mode, which demands an explanation. Table 4 reports best-fit values of $L$ for the different wave components in cases $\mathrm{A}-\mathrm{C}$ using data from Figures 8-10.

5.5.1. Wave-1

[32] The dependence of the wave-1 amplitude on altitude varies significantly between the cases. In case A, it tends to decrease with increasing altitude. In case $\mathrm{B}$, it increases with increasing altitude above $95 \mathrm{~km}$. In case C, it increases with increasing altitude between $75 \mathrm{~km}$ and $90 \mathrm{~km}$, reaching a plateau at higher altitudes.

[33] If the altitude range used to find $L$ is limited to the region where the wave- 1 amplitude increases sharply, then negative values of $L$ are obtained in cases B and C. Specifically, $L$ is $-30 \mathrm{~km}$ between 95 and $110 \mathrm{~km}$ in case B and $-8 \mathrm{~km}$ between 75 and $90 \mathrm{~km}$ in case C, albeit with large uncertainties. Thus the wave- 1 component of the zonal pressure variations in these cases cannot be caused by a single tidal mode. However, negative values of $L$ can be explained by the interaction of multiple tidal modes that combine to produce the observed wave- 1 zonal variation. Although a negative value of $L$ implies the presence of multiple tidal modes, a positive value of $L$ does not necessarily require dominance by a single tidal mode. A negative value of $L$ is the first of two techniques introduced in this work for inferring the presence of multiple tidal modes. This topic is discussed further in sections 6.3 and 7.2.

[34] The wave-1 amplitude decreases with increasing altitude in case A, yet increases with increasing altitude in case $\mathrm{C}$. The only significant difference between these two cases is that case A spans $60^{\circ} \mathrm{S}$ to $30^{\circ} \mathrm{S}$ and case $\mathrm{C}$ spans $20^{\circ}$ $\mathrm{S}$ to $10^{\circ} \mathrm{S}$. Dissipation is clearly important for the tidal mode (s) responsible for the wave-1 component in case A. If the same tidal modes are responsible for the wave-1 components in these two cases, then the relevant dissipative processes are much weaker in the tropics than at higher latitudes. It is noteworthy that the behavior of the wave-1 component in case $\mathrm{C}$ (southern tropics, southern winter) is more similar to case B (northern tropics, northern autumn) than to case A (southern extratropics, southern winter). In both cases $B$ and $C$, the wave- 1 phase is near $150^{\circ} \mathrm{E}$ and the wave-1 amplitude tends to increase with increasing altitude. By contrast, in case A, the wave- 1 phase is near $90^{\circ} \mathrm{E}$ and the wave-1 amplitude decreases almost monotonically with 

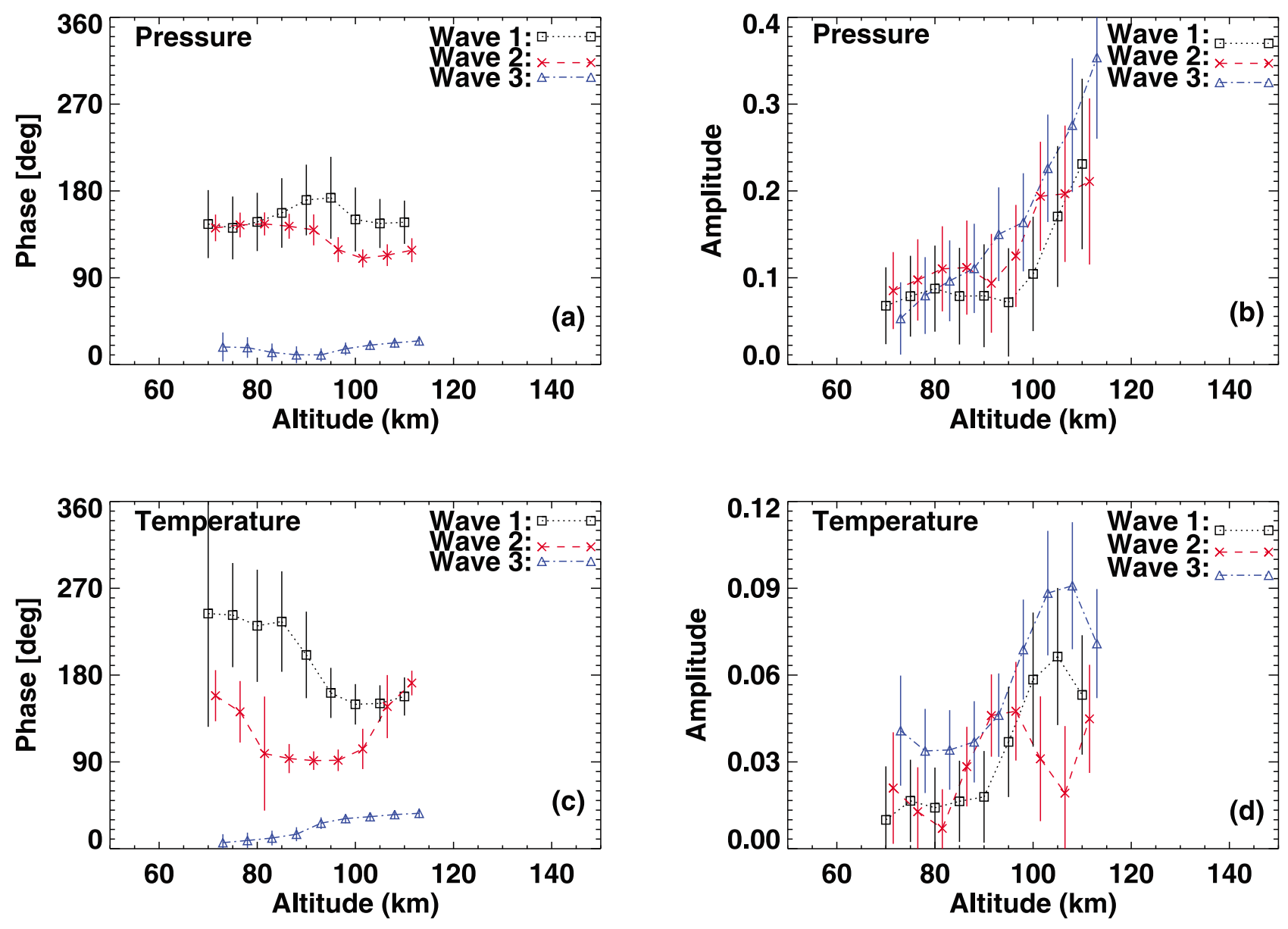

Figure 9. As Figure 8, but for case B.

altitude. This suggests that there is a distinct difference between the tidal modes responsible for the wave-1 component of zonal pressure variations in the tropics and those responsible at higher latitudes.

\subsubsection{Wave-2}

[35] The wave-2 amplitudes change little with altitude below about $90 \mathrm{~km}$ in cases $\mathrm{A}-\mathrm{C}$ but increase rapidly with altitude at higher altitudes. This increase reaches a plateau at high altitudes in case A. If the altitude range used to find $L$ is limited to the region where the wave- 2 amplitude increases sharply, then values of $L$ on the order of $30 \mathrm{~km}$ are obtained in cases A-C, although the uncertainties are very large. Such steep increases in amplitude are consistent with a tidal mode that is only slightly affected by dissipation, which is a characteristic of the DK1 tidal mode [Forbes and Hagan, 2000]. However, this poses the question of why the amplitude of the wave- 2 component is appreciable, rather than negligibly small, below these selected altitude ranges. The likely explanation is that the amplitude of the DK1 tidal mode is extremely small at lower altitudes, but that some other tidal mode that is more sensitive to dissipative processes is responsible for the observed wave- 2 component at lower altitudes. This also provides a natural explanation for the $20^{\circ}$ eastward shift in the wave- 2 phase around $90 \mathrm{~km}$ (section 5.2).

\subsubsection{Wave-3}

[36] The wave-3 amplitudes increase almost monotically with increasing altitude in cases B and $\mathrm{C}$. The data for case A could also be consistent with this trend, but their uncertainties are relatively large. Unlike the wave- 2 component, there is no obvious separation between altitude regions where the amplitude is fairly constant and where the amplitude is increasing dramatically, which suggests that the same tidal mode is responsible for the wave- 3 component at all altitudes. This is also consistent with the observed steady drifts in wave-3 phase with altitude, as opposed to an abrupt, step-like change at some altitude (section 5.2).

\section{Variations in Temperature With Longitude in SPICAM Observations}

[37] An important feature of the SPICAM data set is that atmospheric densities, pressures, and temperatures are all determined as functions of altitude. By contrast, data sets provided by orbiting infrared instruments, such as the Thermal Emission Spectrometer (TES) on MGS [Banfield et al., 2000, 2003; Smith et al., 2001; Smith, 2004] or Mars Climate Sounder (MCS) on MRO [McCleese et al., 2007; Lee et al., 2009; Heavens et al., 2010], are limited to temperature as functions of pressure. The additional information provided 

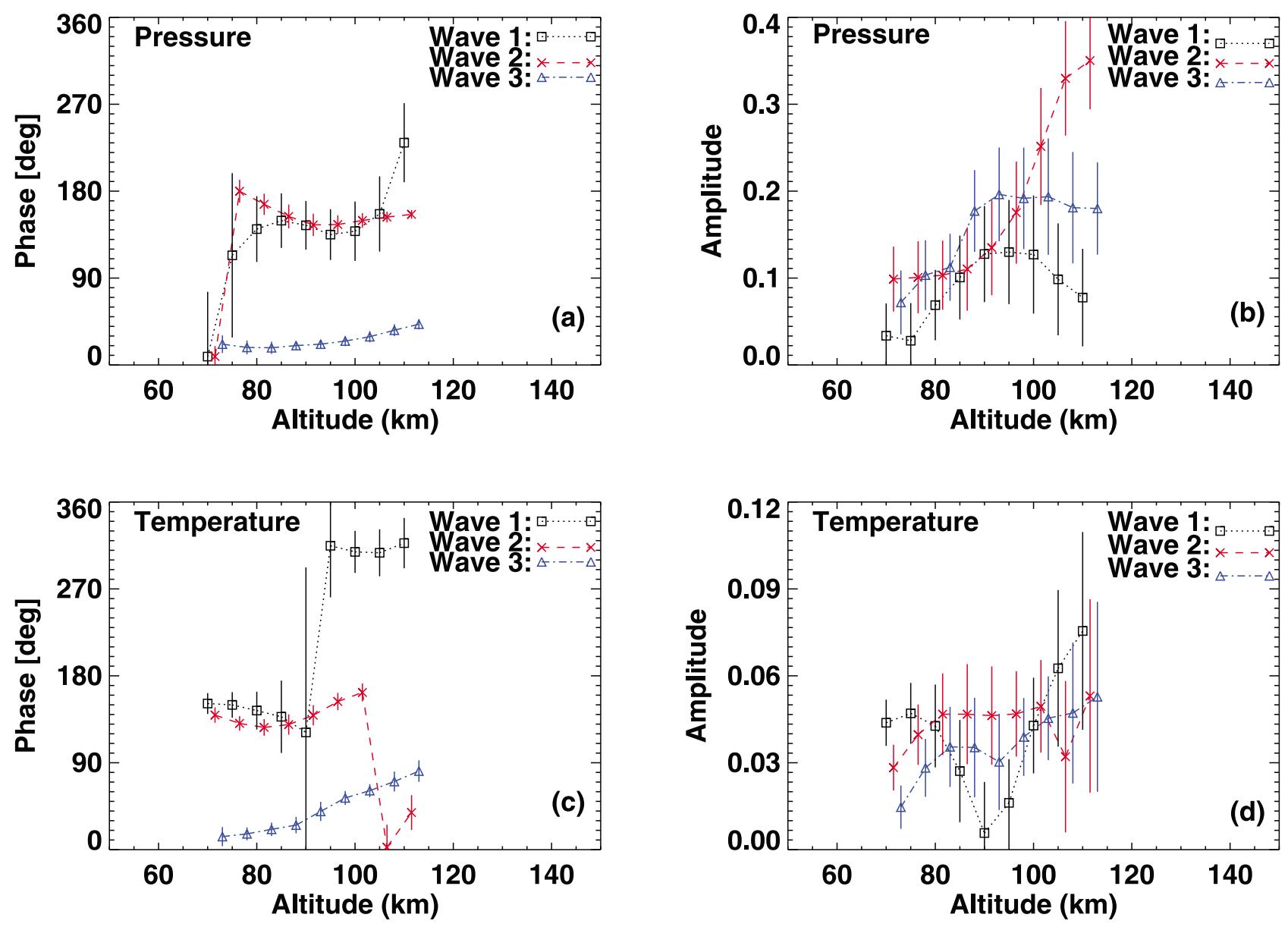

Figure 10. As Figure 8, but for case C.

by SPICAM's absolute altitude scale is helpful for investigating atmospheric properties and processes.

[38] Figure 11 illustrates that substantial variations in temperature with longitude at fixed altitude are apparent in SPICAM observations. As for pressure, these variations are caused by thermal tides. Fitted amplitudes and phases are reported in Tables 5-8. We now develop theoretical relationships between temperature and pressure variations, before comparing specific predictions to observations in the subsequent sections.

\subsection{Theory}

[39] The following theoretical analysis demonstrates why zonal variations in pressure due to nonmigrating thermal tides also cause zonal variations in temperature. Suppose the dependence of pressure, $p$, on longitude, $\lambda$, and altitude, $z$, satisfies

$$
p=p_{0}(z)\left(1+w_{p}(z) f(\lambda)\right)
$$

where $w_{p}(z)$ is a normalized amplitude (dimensionless) and the maximum value of $|f(\lambda)|$ (also dimensionless) is unity. We define a zonally uniform scale height, $H_{0}$, by

$$
\frac{d \ln p_{0}}{d z}=\frac{-1}{H_{0}}
$$

Since the scale height, $H$, is defined by $d \ln p / d z=-1 / H$, it can be shown that $H$ satisfies

$$
H=H_{0}\left(1+H_{0} \frac{d w_{p}(z)}{d z} f(\lambda)\right)
$$

This result is valid if $w_{p}(z)$ is small, $H_{0} d w_{p}(z) / d z$ is small, and $f(\lambda)$ does not vary greatly with altitude. Since temperature, $T$, is proportional to $H$, a similar expression describes zonal temperature variations. Specifically, $H / H_{0}=T / T_{0}$. Because equation (4) is linear in $f(\lambda)$, each wave- $n$ component of zonal temperature variations is controlled by the

Table 4. Values of $L$ for the Wave-1, Wave-2, and Wave-3 Components of Cases A-C

\begin{tabular}{lcr}
\hline Case & Wave- $n$ & \multicolumn{1}{c}{$L(\mathrm{~km})$} \\
\hline A & 1 & $9.0 \pm 1.3$ \\
A & 2 & $24.2 \pm 7.5$ \\
A & 3 & $17.8 \pm 3.2$ \\
B & 1 & $18.5 \pm 0.9$ \\
B & 2 & $21.4 \pm 0.6$ \\
B & 3 & $31.4 \pm 15.7$ \\
C & 1 & $24.8 \pm 15.9$ \\
C & 2 & $22.7 \pm 3.1$ \\
C & 3 & $29.0 \pm 11.6$ \\
\hline
\end{tabular}



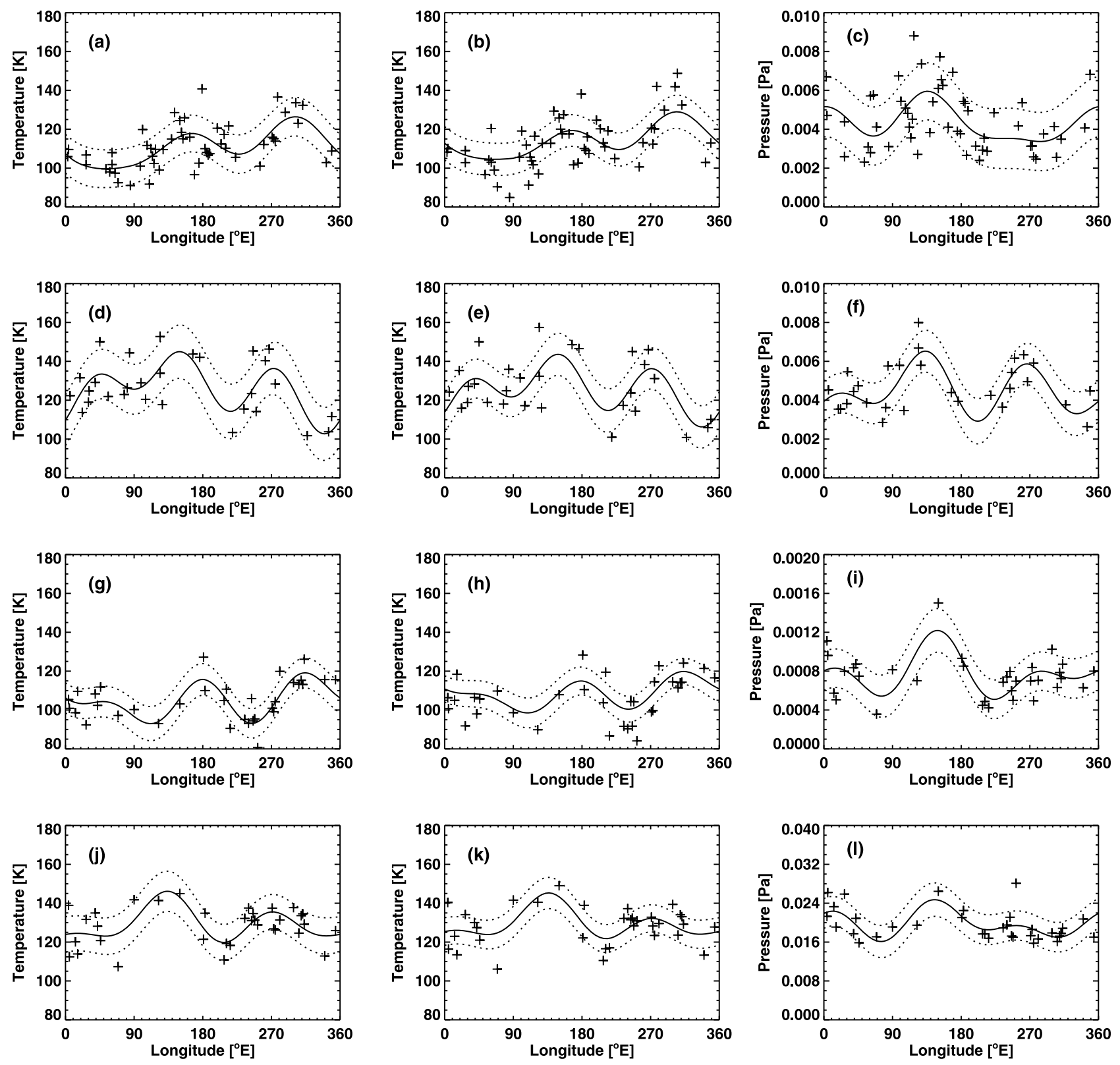

Figure 11. $(\mathrm{a}-\mathrm{c})$ Case $\mathrm{A}$, where Figure 11a shows temperature measurements at $0.005 \mathrm{~Pa}$ and fit with symbols as Figure 2. Figure $11 \mathrm{~b}$ shows temperature measurements at $90 \mathrm{~km}$ and fit. Figure $11 \mathrm{c}$ shows pressure measurements at $90 \mathrm{~km}$ and fit. Pressure and temperature phases are anticorrelated for the wave-1 and wave- 3 components. (d-f) Similar temperature and pressure data for case B at $0.005 \mathrm{~Pa}$ in Figure $11 \mathrm{~d}$ and $100 \mathrm{~km}$ in Figures 11e and 11f. Pressure and temperature phases are correlated for the wave-1 and wave- 2 components. (g-i) Similar temperature and pressure data for case $\mathrm{C}$ at $0.001 \mathrm{~Pa}$ in Figure $11 \mathrm{~g}$ and $100 \mathrm{~km}$ in Figures $11 \mathrm{~h}$ and 11i. Pressure and temperature phases are anti-correlated for the wave- 1 component and correlated for the wave-2 component. (j-1) Similar temperature and pressure data for case $\mathrm{C}$ at $0.02 \mathrm{~Pa}$ in Figure $11 \mathrm{j}$ and $80 \mathrm{~km}$ in Figures $11 \mathrm{k}$ and 111. Pressure and temperature phases are anticorrelated for the wave- 1 and wave- 3 components. In all four rows, zonal variations in temperature at fixed pressure are similar to those at fixed altitude.

corresponding wave- $n$ component of zonal pressure variations. Equation (4) leads to several testable predictions.

[40] First, the phase of a component of zonal temperature variations equals the corresponding pressure phase if $d w_{p}(z) / d z$ is positive. Second, the phase of a component of zonal temperature variations differs by half of its full range $\left(360^{\circ} \mathrm{E} / n\right)$ from the corresponding pressure phase if $d w_{p}(z) / d z$ is negative. Third, the amplitude of a component of zonal temperature variations is zero if the corresponding $d w_{p}(z) / d z$ is zero (and vice versa). Fourth, the nonzero amplitude of a component of zonal temperature variations equals $H_{0} d w_{p}(z) / d z$. Fifth, the phase of a component of zonal temperature variations changes by half of its full range if the sign of 
Table 5. Fitted Temperature Amplitudes and $1 \sigma$ Uncertainties for $90 \mathrm{~km}$ in Case A, $100 \mathrm{~km}$ in Case B, $80 \mathrm{~km}$ in Case $\mathrm{C}$, and $100 \mathrm{~km}$ in Case $\mathrm{C}^{\mathrm{a}}$

\begin{tabular}{lrccrr}
\hline Case & $z(\mathrm{~km})$ & $T_{0}(\mathrm{~K})$ & $w_{T 1}$ & $w_{T 2}$ & $w_{T 3}$ \\
\hline A & 90 & $1.14 \mathrm{E}+02 \pm 1.16 \mathrm{E}+00$ & $0.06 \pm 0.01$ & $0.06 \pm 0.02$ & $0.03 \pm 0.01$ \\
B & 100 & $1.26 \mathrm{E}+02 \pm 2.05 \mathrm{E}+00$ & $0.06 \pm 0.02$ & $0.03 \pm 0.02$ & $0.09 \pm 0.02$ \\
C & 80 & $1.30 \mathrm{E}+02 \pm 1.32 \mathrm{E}+00$ & $0.04 \pm 0.01$ & $0.05 \pm 0.01$ & $0.04 \pm 0.01$ \\
C & 100 & $1.08 \mathrm{E}+02 \pm 1.26 \mathrm{E}+00$ & $0.04 \pm 0.02$ & $0.05 \pm 0.02$ & $0.05 \pm 0.01$ \\
\hline
\end{tabular}

${ }^{\mathrm{a}}$ The term $T_{0}$ is the fitted zonally uniform temperature $(\mathrm{K})$ and $w_{T n}$ is the normalized amplitude of the wave- $n$ component (dimensionless).

$d w_{p}(z) / d z$ reverses with increasing altitude (and vice versa). The subsequent parts of section 6 test these predictions.

[41] We say that a temperature phase and a pressure phase are correlated if they are identical and anticorrelated if they differ by half of their full range. Correlation is predicted to occur if a particular dominant tidal mode intensifies (amplitude increases with increasing altitude). Anticorrelation is predicted to occur if a particular dominant tidal mode attenuates (amplitude decreases with increasing altitude). An intuitive sense of this relationship arises from the following illustration. Suppose pressures at $80 \mathrm{~km}$ are greater than the zonal mean at $0^{\circ} \mathrm{E}$ and less than the zonal mean at $180^{\circ} \mathrm{E}$, and that pressures at $120 \mathrm{~km}$ are zonally symmetric. The zonal structure has attenuated, not intensified, between $80 \mathrm{~km}$ and $120 \mathrm{~km}$. The change in pressure from $80 \mathrm{~km}$ to $120 \mathrm{~km}$ is larger at $0^{\circ} \mathrm{E}$ than at $180^{\circ} \mathrm{E}$, so the scale height must be smaller at $0^{\circ} \mathrm{E}$ than at $180^{\circ} \mathrm{E}$. Hence pressures and scale heights/temperatures are anticorrelated in this illustration.

\subsection{Variations in Phase With Altitude}

[42] Figures 8-10 show variations in the phases and amplitudes of harmonic components for temperature with altitude for cases A-C. Although the uncertainties on the fitted amplitudes are quite large for some of the points plotted in Figures 8-10, the associated phases have clear trends with altitude, which indicates that these zonal variations in temperature are meaningful, rather than fitted noise.

[43] In most instances, the phases shown in Figures 8-10 vary smoothly with altitude. There are three exceptions where the phase changes abruptly with altitude, the wave-1 component of cases A $(80 \mathrm{~km})$ and C $(90 \mathrm{~km})$ and the wave-3 component of case A $(85 \mathrm{~km})$. In all three of these instances, the phase changes by one-half of its full range, $180^{\circ}$ for the wave- 1 components and $60^{\circ}$ for the wave- 3 component, and the value of the corresponding amplitude is consistent with zero. The amplitudes of the corresponding pressure components are local maxima, so the sign of $d w_{p}(z) / d z$ reverses in each instance as well.
[44] Figure 11 shows several examples of zonal variations in pressure and temperature at fixed altitude (discussed further in section 6.4). It also illustrates that zonal variations in temperature at a fixed pressure level are very similar to the zonal variations at fixed altitude that our theoretical discussions concentrate on. This excludes the possibility that the zonal variations in temperature at fixed altitude reflect a zonally uniform $\mathrm{T}(\mathrm{p})$ that is sampled at different pressures as longitude changes at constant altitude, which could occur if the only impact of tides was the rise and fall of the atmospheric column. Therefore the zonal variations in temperature at fixed altitude result from adiabatic heating/cooling caused by the atmospheric motions associated with nonmigrating tides.

\subsection{Phase Reversals and Inferred Number of Tidal Modes}

[45] However, there are several other extrema in the pressure amplitudes that are not associated with reversals in temperature phase and zero temperature amplitude. For case A, these include wave-2 at $80 \mathrm{~km}$ and wave- 3 at $105 \mathrm{~km}$. For case B, these include wave-1 at $80 \mathrm{~km}$ and $95 \mathrm{~km}$ and wave-2 at $80 \mathrm{~km}$ and $90 \mathrm{~km}$. For case C, these include wave- 1 around $100 \mathrm{~km}$ and wave- 2 at $90 \mathrm{~km}$. It is likely that some of the extrema in fitted amplitude may not correspond to extrema in real amplitudes due to uncertainties in the fits, but this explanation cannot eliminate all of these extrema in fitted amplitude.

[46] The predictions derived from equation (4) require that $f(\lambda)$ does not vary greatly with altitude. If two or more tidal modes contribute to a particular component of zonal pressure variations, then the individual amplitudes and phases of both modes contribute to the net $w_{p}(z)$ and $f(\lambda)$. If their individual amplitudes vary with altitude at different rates, as is plausible, then the gradient in the net $w_{p}(z)$ can be zero without the net temperature amplitude being zero and the gradient in the net $w_{p}(z)$ can reverse sign without the net temperature phase changing abruptly by half a cycle.

Table 6. Fitted Pressure Amplitudes and $1 \sigma$ Uncertainties for $90 \mathrm{~km}$ in Case A, $100 \mathrm{~km}$ in Case B, $80 \mathrm{~km}$ in Case $\mathrm{C}$, and $100 \mathrm{~km}$ in Case $\mathrm{C}^{\mathrm{a}}$

\begin{tabular}{lrllll}
\hline Case & $z(\mathrm{~km})$ & $p_{0}(\mathrm{~Pa})$ & $w_{p 1}$ & $w_{p 2}$ & $w_{p 3}$ \\
\hline $\mathrm{A}$ & 90 & $4.34 \mathrm{E}-03 \pm 2.09 \mathrm{E}-04$ & $0.16 \pm 0.07$ & $0.17 \pm 0.07$ & $0.12 \pm 0.07$ \\
$\mathrm{~B}$ & 100 & $4.51 \mathrm{E}-03 \pm 2.09 \mathrm{E}-04$ & $0.10 \pm 0.07$ & $0.19 \pm 0.06$ & $0.23 \pm 0.06$ \\
$\mathrm{C}$ & 80 & $1.98 \mathrm{E}-02 \pm 5.71 \mathrm{E}-04$ & $0.07 \pm 0.04$ & $0.10 \pm 0.04$ & $0.11 \pm 0.04$ \\
$\mathrm{C}$ & 100 & $7.77 \mathrm{E}-04 \pm 3.74 \mathrm{E}-05$ & $0.13 \pm 0.07$ & $0.25 \pm 0.07$ & $0.19 \pm 0.07$ \\
\hline
\end{tabular}

${ }^{\mathrm{a}}$ The term $p_{0}$ is the fitted zonally uniform pressure (Pascals) and $w_{p n}$ is the normalized amplitude of the wave- $n$ component (dimensionless). 
Table 7. Fitted Temperature Phases and $1 \sigma$ Uncertainties for $90 \mathrm{~km}$ in Case A, $100 \mathrm{~km}$ in Case B, $80 \mathrm{~km}$ in Case C, and $100 \mathrm{~km}$ in Case $\mathrm{C}^{\mathrm{a}}$

\begin{tabular}{lrrrr}
\hline Case & $z(\mathrm{~km})$ & \multicolumn{1}{c}{$\phi_{T 1}$} & \multicolumn{1}{c}{$\phi_{T 2}$} & \multicolumn{1}{c}{$\phi_{T 3}$} \\
\hline A & 90 & $272.1 \pm 13.7$ & $140.6 \pm 6.4$ & $56.1 \pm 10.2$ \\
B & 100 & $149.7 \pm 21.0$ & $103.4 \pm 20.9$ & $33.2 \pm 4.7$ \\
C & 80 & $144.0 \pm 19.5$ & $126.6 \pm 8.6$ & $21.1 \pm 7.0$ \\
C & 100 & $308.4 \pm 21.8$ & $162.8 \pm 9.3$ & $61.1 \pm 6.7$ \\
\hline
\end{tabular}

${ }^{\mathrm{a}}$ The term $\phi_{T n}$ is the phase of the wave- $n$ component (degrees).

[47] We conclude, as long as the other assumptions required by equation (4) are not violated, that the existence of an extremum in the amplitude for a particular pressure component that is not accompanied by a reversal in the corresponding temperature phase and by a corresponding temperature amplitude of zero strongly suggests that this harmonic component is composed of multiple underlying disturbances, not a single tidal mode. This is the second of two techniques introduced in this work for inferring the presence of multiple tidal modes. This topic is discussed further in sections 5.5.1 and 7.2.

\subsection{Phase Correlations and Anticorrelations}

[48] When a component is dominated by a single tidal mode and the pressure amplitude changes with altitude, equation (4) predicts either correlation or anticorrelation between the temperature and pressure phases. There are many instances where clear changes in pressure amplitude with altitude are associated with the expected phase relationship. For wave-1, phase correlations are present in case $\mathrm{A}$ at $70 \mathrm{~km}$, case B at $100 \mathrm{~km}$, and case C at $80 \mathrm{~km}$ and a phase anticorrelation is present in case $A$ at $90 \mathrm{~km}$. For wave-2, phase correlations are present in case A at $90 \mathrm{~km}$, case $B$ at $100 \mathrm{~km}$, and case $\mathrm{C}$ at $100 \mathrm{~km}$. For wave-3, phase correlations are present in case A at $80 \mathrm{~km}$, case B at $80 \mathrm{~km}$, and case $C$ at $80 \mathrm{~km}$. Phase anticorrelations are also present in case A at $90 \mathrm{~km}$ for wave-3 and case C at $100 \mathrm{~km}$ for wave-1, although the gradient in the fitted $w_{p}(z)$ is not clearly negative. Each of the three phase anticorrelations are associated with one of the three temperature phase reversals discussed in section 6.2.

[49] Figure 11 shows examples of phase correlations and anticorrelations. Tables 5-8 report the corresponding fitted amplitudes and phases.

[50] It is unclear why a phase correlation exists in case B for wave- 1 at $100 \mathrm{~km}$. Two pieces of evidence suggest that multiple tidal modes contribute to this component, a pressure minimum at $95 \mathrm{~km}$ is not associated with a reversal in temperature phase (that would require phase anticorrelation in the $80-90 \mathrm{~km}$ range) and $L<0$ in the $95-110 \mathrm{~km}$ range.

Table 8. Fitted Pressure Phases and $1 \sigma$ Uncertainties for $90 \mathrm{~km}$ in Case A, $100 \mathrm{~km}$ in Case B, $80 \mathrm{~km}$ in Case C, and $100 \mathrm{~km}$ in Case $\mathrm{C}^{\mathrm{a}}$

\begin{tabular}{lrrrr}
\hline Case & $z(\mathrm{~km})$ & \multicolumn{1}{c}{$\phi_{p 1}$} & \multicolumn{1}{c}{$\phi_{p 2}$} & \multicolumn{1}{c}{$\phi_{p 3}$} \\
\hline A & 90 & $100.0 \pm 25.9$ & $155.4 \pm 11.5$ & $9.4 \pm 11.1$ \\
B & 100 & $150.4 \pm 33.2$ & $110.1 \pm 9.3$ & $20.2 \pm 5.2$ \\
C & 80 & $140.8 \pm 34.1$ & $166.4 \pm 11.0$ & $17.8 \pm 6.3$ \\
C & 100 & $138.5 \pm 30.7$ & $149.7 \pm 7.6$ & $29.3 \pm 5.9$ \\
\hline
\end{tabular}

${ }^{\mathrm{a}}$ The term $\phi_{p n}$ is the phase of the wave- $n$ component (degrees).
Table 9. Predicted and Observed Normalized Temperature Amplitudes With $1 \sigma$ Uncertainties for Three Instances

\begin{tabular}{lcccc}
\hline Case & $z(\mathrm{~km})$ & Wave- $n$ & Observed & Predicted \\
\hline A & 90 & 2 & $0.08 \pm 0.02$ & $0.06 \pm 0.03$ \\
C & 80 & 3 & $0.05 \pm 0.02$ & $0.04 \pm 0.02$ \\
C & 100 & 2 & $0.07 \pm 0.02$ & $0.09 \pm 0.03$ \\
\hline
\end{tabular}

The $90^{\circ}$ change in wave- 1 phase with altitude for case B also lacks a straight-forward explanation. In addition, it is unclear why a phase correlation exists in case $C$ for wave-1 at $80 \mathrm{~km}$ when $L$ is negative around this altitude.

\subsection{Predicted Temperature Amplitudes}

[51] Equation (4) predicts the amplitude of a temperature component. In most instances, the uncertainties on the predicted and observed amplitudes are so large that the accuracy of the predictions can scarcely be evaluated. Three of the most successful predictions are summarized in Table 9. All three instances correspond to significant increases in the pressure amplitude with altitude that are sustained over an appreciable vertical distance. All three are also associated with phase correlations.

\section{Summary and Conclusions}

[52] Zonal variations at fixed altitude, latitude, season, and local time can be seen in pressure and temperature measurements at $70-120 \mathrm{~km}$ from the SPICAM instrument. These are caused by nonmigrating thermal tides.

\subsection{Dominant Modes}

[53] Wave-2 and wave-3 components are usually the strongest, consistent with higher altitude observations and theoretical predictions. The amplitudes of the strongest pressure variations have not begun to decrease significantly by $110 \mathrm{~km}$, yet the amplitudes of density variations in aerobraking accelerometer observations decrease above $130 \mathrm{~km}$. Although most work using aerobraking accelerometer data to study thermal tides has focused on $120 \mathrm{~km}$ or above, there are substantial data in the $100-120 \mathrm{~km}$ range that might span the peak amplitudes of the most significant tidal modes. As was found in aerobraking density data at $130-160 \mathrm{~km}$, phases of harmonic components of pressure variations vary little with altitude. Data from cases A-C of this work and the nightside observations reported by Withers [2003] have similar density or pressure phases for both their wave-2 and wave- 3 components. These four data sets sample the same local time, but a range of latitudes and seasons. This raises the question of whether the phases of the dominant nonmigrating tidal modes in the Martian atmosphere are determined solely by characteristics of the Martian surface and are thereby relatively insensitive to atmospheric conditions.

\subsection{Theoretical Relationships}

[54] Straightforward theory leads to several testable predictions concerning relationships between zonal variations in pressure and temperature for harmonic components dominated by a single tidal mode. Each prediction has been confirmed observationally in multiple instances. We have developed and applied two techniques for testing whether a given harmonic component contains contributions from 
several aliased tidal modes or is dominated by a single tidal mode. A strong intensification in pressure amplitude that has a negative value of the dissipative length scale, $L$, indicates multiple tidal modes. Failure to satisfy the predicted relationships between pressure and temperature also indicates multiple tidal modes. Satisfying these predicted relationships indicates a single tidal mode.

\subsection{Wave-1}

[55] The wave- 1 component is the most complex of the three studied here. In case B we infer from pressure amplitude extrema at $80 \mathrm{~km}$ and $95 \mathrm{~km}$ that are not accompanied by temperature phase reversals and from its negative $(-30 \mathrm{~km}$, but highly uncertain) value of $L$ between 95 and $110 \mathrm{~km}$ that its wave-1 component contains multiple tidal modes at all altitudes. In case $\mathrm{C}$ we infer from a pressure amplitude extremum at $90 \mathrm{~km}$ that is accompanied by a temperature phase reversal and from its negative $(-8 \mathrm{~km}$, but highly uncertain) value of $L$ at 75-90 km that its wave- 1 component contains multiple tidal modes at low altitudes but is dominated by a single tidal mode at high altitudes. In case A we infer from a pressure amplitude extremum at $90 \mathrm{~km}$ that is accompanied by a temperature phase reversal that its wave- 1 component is dominated by a single tidal mode at low altitudes. The corresponding positive value of $L$ and stable pressure phase are also consistent with a single tidal mode.

[56] The behavior of the wave-1 component differs between the tropics (case C) and extratropics (case A). In the tropics, it is dominated by a single tidal mode at $80 \mathrm{~km}$, has increasing pressure amplitude with increasing altitude at 90 $110 \mathrm{~km}$, and a phase of $150^{\circ}$ at $80-90 \mathrm{~km}$. In the extratropics, it contains multiple tidal modes at $80 \mathrm{~km}$, has decreasing pressure amplitude with increasing altitude at $90-110 \mathrm{~km}$, and a phase of $90^{\circ}$ at $80-90 \mathrm{~km}$. These characteristics are constraints that must be satisfied by simulations that predict which tidal modes are present in the atmosphere. The behavior of the wave- 1 component in Case B is also atypical, the pressure amplitude is unusually strong and the temperature phase is consistent with a constant value below $90 \mathrm{~km}$, shifts westward $90^{\circ}$ at $90 \mathrm{~km}$, then settles at a constant value above $90 \mathrm{~km}$.

\subsection{Wave-2}

[57] A transition in the behavior of the wave-2 component occurs at $80 \mathrm{~km}$ in case A and $90 \mathrm{~km}$ in cases B and C. Pressure amplitudes are around 0.1 and vary little with altitude below these transition altitudes but are larger and increase strongly with increasing altitude above. Pressure phases change abruptly eastward by $20^{\circ}$ at these transition altitudes. Pressure amplitude extrema at these transition altitudes are not accompanied by a temperature phase reversal, suggesting multiple tidal modes, but phase correlations and accurate temperature amplitude predictions occur at higher altitudes, suggesting a single tidal mode. We conclude that the wave- 2 component contains multiple tidal modes below this transition altitude but is dominated by a single tidal mode, DK1, at higher altitudes. DK1 is also favored by the meridionally broad extent inferred from the similarities of the wave- 2 pressure phases at high altitudes in cases $\mathrm{A}$ and $\mathrm{C}$, by phase changes with local time between nightside cases $\mathrm{A}$ and $\mathrm{C}$ observations and dayside aerobraking density data, and the large, positive values of $L$ at high altitudes. Possible candidates for other modes contributing to the wave- 2 component include the $n=1, s=3$ tidal mode [Hinson et al., 2008]. Although most observational and theoretical studies have concluded that DK1 always dominates the wave- 2 component of zonal density/ pressure variations, DK1 is not always strong above $90 \mathrm{~km}$, the wave- 2 pressure amplitude is very weak for case D.

\subsection{Wave-3}

[58] In the cases studied here, the wave- 3 component is always consistent with dominance by a single tidal mode. There are many instances where a predicted relationship between pressure and temperature is satisfied, but none where a prediction clearly fails. Its pressure amplitude tends to increase steadily with increasing altitude between $70 \mathrm{~km}$ and $110 \mathrm{~km}$, rather than oscillating wildly. Its pressure phase changes gradually with increasing altitude between $70 \mathrm{~km}$ and $110 \mathrm{~km}$, and its value of $L$ is around $20-30 \mathrm{~km}$. A diurnal period is suggested by phase changes with local time between nightside cases $\mathrm{A}$ and $\mathrm{C}$ observations and dayside aerobraking density data, which makes DK2 the most likely dominant tidal mode at these tropical and extratropical latitudes. Other results suggest that SK1 is stronger than DK2 at more poleward latitudes.

\subsection{Anticipated Impact of Mars Climate Sounder Data}

[59] The behavior of thermal tides in the middle and upper atmosphere during dusty conditions, which may be important for case B, can be further studied in MGS Phase 1 aerobraking data that were affected by the Noachis dust storm. Although most work to date on thermal tides in the upper atmosphere has used MGS Phase 2 aerobraking data, useful comparative data are also available from MGS Phase 1, Odyssey, and MRO aerobraking observations. The problem of sparse observations, which affects data sets from both occultation and aerobraking instruments, can be overcome by the large Mars Climate Sounder data set [McCleese et al., 2007; Kleinböhl et al., 2009; Lee et al., 2009; Heavens et al., 2010], which appears extremely well-suited to studies of thermal tides in the middle atmosphere. It offers near-complete seasonal and meridional coverage over an extended vertical region at two local times separated by half a sol and provides a sufficient number of observations for averaging to minimize measurement uncertainties.

\section{Appendix A}

[60] The direct solar forcing can be represented as a series of terms whose frequencies are integer multiples of the reciprocal of the length of the Martian solar day (diurnal, semidiurnal, ter-diurnal, etc., terms), and hence thermal tides are limited to the same set of temporal frequencies. Diurnal and semidiurnal terms are typically dominant. Tidal oscillations, which must contain an integer number of cycles per $360^{\circ}$, are also restricted in how they may vary with longitude. Accordingly, any tidal oscillation can be represented as [Forbes et al., 2002]

$$
\sum_{n} \sum_{s} A_{n, s}(z, \theta) \cos \left(n \Omega t+s \lambda-\phi_{n, s}(z, \theta)\right)
$$

where $A$ is an amplitude, $z$ is altitude, $\theta$ is latitude, $n$ is a nonnegative integer, $\Omega$ is the planetary rotation rate, $t$ is 
universal time, $s$ is an integer, $\lambda$ is east longitude, and $\phi$ is a phase. Components with $n=0,1,2, \ldots$ are stationary, diurnal, semidiurnal, ... components, respectively. The absolute value of $s$ is the number of cycles per $360^{\circ}$ of longitude. Components with $s>0, s<0$, and $s=0$ are westward propagating, eastward propagating, and zonally symmetric, respectively. Since $\Omega t=\Omega t_{L S T}-\lambda$, where $t_{L S T}$ is local solar time, equation (A1) can also be written as

$$
\sum_{n} \sum_{s} A_{n, s}(z, \theta) \cos \left(n \Omega t_{L S T}+(s-n) \lambda-\phi_{n, s}(z, \theta)\right)
$$

Solar forcing contains only components with $s=n$, which move with respect to an observer on the ground at the same speed as the Sun in the sky. On a zonally symmetric planet, only tidal components with $s=n$ are present. Tidal components that have $s=n$ are "migrating" tides and those that do not are "nonmigrating" tides. Migrating tides appear independent of longitude in a reference frame in which local time is fixed. To an observer whose position is fixed relative to the surface of Mars, migrating tides have the same zonal phase speed as the Sun. Nonmigrating components are produced by the interaction of solar forcing with zonally asymmetric conditions. For Mars, zonal asymmetries in topography, surface thermal inertia, surface albedo, lower atmospheric dust distribution and nonlinear wave-wave interactions are possible sources of nonmigrating tidal components [Forbes et al., 2002; Withers et al., 2003; Forbes, 2004; Angelats $i$ Coll et al., 2004; Moudden and Forbes, 2008a].

[61] In this work, we focus on observations in a fixed local solar time reference frame, where nonmigrating tides can cause variations with longitude, but migrating tides cannot. The variation with local solar time and longitude of a migrating tidal component whose zonal wave number is $s_{X}$ satisfies

$$
\begin{gathered}
\cos \left(s_{X} \Omega t+s_{X} \lambda-\phi_{S_{X}, s_{X}}\right) \\
\cos \left(s_{X} \Omega t_{L S T}+\left(s_{X}-s_{X}\right) \lambda-\phi_{S_{X}, s_{X}}\right)
\end{gathered}
$$

where terms like $\left(s_{X}-s_{X}\right)$ are retained for clarity. If zonal asymmetries are represented by

$$
\cos \left(m \lambda-\phi_{m}\right)
$$

where $m$ is a positive integer and $\phi_{m}$ is a phase, then their interactions with migrating tidal components generate sumand-difference components that satisfy

$$
\begin{gathered}
\cos \left(s_{X} \Omega t+\left(s_{X} \pm m\right) \lambda-\left(\phi_{S_{X}, S_{X}} \pm \phi_{m}\right)\right) \\
\cos \left(s_{X} \Omega t_{L S T}+\left(\left(s_{X}-s_{X}\right) \pm m\right) \lambda-\left(\phi_{S_{X}, s_{X}} \pm \phi_{m}\right)\right)
\end{gathered}
$$

[62] A tidal component described by equations (A6) and (A7) has a period that is given by $s_{X}$, a true zonal wave number of $\left(s_{X} \pm m\right)$ and a zonal wave number in a fixed local solar time reference frame of $\mathrm{I}\left(s_{X}-s_{X}\right) \pm m \mathrm{l}$, which reduces to $m$ for all values of $s_{X}$. An observer at a fixed longitude who records the atmospheric response to a tidal component over all local solar times is able to determine its period but neither its true zonal wave number nor $m$. An observer who records the atmospheric response to a tidal component over all longitudes at a fixed local solar time is able to determine $m$. This observer can place constraints on the period and true zonal wave number but cannot uniquely determine them [e.g., Hinson et al., 2008]. If these observations are extended to a second local solar time that differs significantly from the original local solar time, then the period of the tidal component can be determined. For a difference of half a day, the longitudes of tidal maxima and minima are reversed for a diurnal tidal component, but unchanged for a semidiurnal tidal component. Consider, for example, a wave-1 zonal harmonic in a series of observations at fixed local solar time. It could be produced by any of the following tidal components, assuming that only diurnal and semidiurnal components are considered:

$$
\begin{aligned}
& \cos \left(1 \Omega t_{L}+0 \lambda\right) \\
& \cos \left(1 \Omega t_{L}+2 \lambda\right) \\
& \cos \left(2 \Omega t_{L}+1 \lambda\right) \\
& \cos \left(2 \Omega t_{L}+3 \lambda\right)
\end{aligned}
$$

[63] The period and true zonal wave number often strongly influence the vertical and meridional structure of $A$ $(z, \theta)$ [Chapman and Lindzen, 1970; Forbes, 1995]. In idealized tidal theory, the variation of each $(s, n)$ tidal component with latitude can be represented as the sum of a series of Hough functions, where each Hough function is identified by a label $i$ [Chapman and Lindzen, 1970; Forbes, 1995]. An $(s, n)$ tidal component is often dominated by the one $(s, n, i)$ Hough mode whose meridional dependence approximates that of solar heating (symmetric about the equator, no nodes close to the equator, and maximized at the equator rather than the poles). Also, each Hough function has a specific dependence on altitude, either an exponential decay (evanescent) or harmonic oscillation (propagating), that is characterized by a single vertical wavelength. Evanescent Hough modes that have small vertical wavelengths are rarely important at high altitudes. In the absence of dissipation, the conservation of energy dictates that the amplitude of a propagating Hough mode grows exponentially with altitude as density decreases. Even so, amplitudes cannot increase without limit. Idealized tidal theory is only valid when amplitudes are small, and a Hough mode whose amplitude monotonically increases eventually "breaks," distributing its energy and momentum into a range of disturbances with smaller spatial scales.

[64] Identification of the underlying tidal component responsible for an observed atmospheric oscillation is often an objective in atmospheric science, and several methods can be applied to accomplish this. Observations can constrain periods and zonal wave numbers using equations (A6)-(A7). Changes in the amplitude and phase of the observed atmospheric oscillation with latitude and altitude can also be used to distinguish between possible tidal components. 
[65] Acknowledgments. We acknowledge thoughtful and constructive reviews from Francois Forget and Tamara McDunn. Mars Express is a European Space agency mission. J.L.B. and F.M. acknowledge support from CNES. P.W. and R.P. acknowledge partial support from NASA MDAP grant NNX08AK96G and helpful discussions with Jeff Forbes and Youssef Moudden.

\section{References}

Andrews, D. G., J. R. Holton, and C. B. Leovy (1987), Middle Atmosphere Dynamics, Academic, San Diego, Calif.

Angelats i Coll, M., F. Forget, M. A. López-Valverde, P. L. Read, and S. R. Lewis (2004), Upper atmosphere of Mars up to $120 \mathrm{~km}$ : Mars Global Surveyor accelerometer data analysis with the LMD general circulation model, J. Geophys. Res., 109, E01011, doi:10.1029/2003JE002163.

Banfield, D., B. Conrath, J. C. Pearl, M. D. Smith, and P. Christensen (2000), Thermal tides and stationary waves on Mars as revealed by Mars Global Surveyor Thermal Emission Spectrometer, J. Geophys. Res., 105, 9521-9538.

Banfield, D., B. J. Conrath, M. D. Smith, P. Christensen, and R. J. Wilson (2003), Forced waves in the martian atmosphere from MGS TES nadir data, Icarus, 161, 319-345.

Barth, C. A., A. I. F. Stewart, S. W. Bougher, D. M. Hunten, S. J. Bauer, and A. F. Nagy (1992), Aeronomy of the current martian atmosphere, in Mars, edited by H. H. Kieffer et al., pp. 1054-1089, Univ. of Ariz. Press, Tucson.

Bertaux, J.-L., et al. (2004), SPICAM: Studying the global structure and composition of the Martian atmosphere, in Mars Express: The Scientific Payload, edited by A. Wilson, Eur. Space Agency Spec. Publ., SP-1240, 95-120. (Available at http://sci.esa.int/science-e/www/object/index.cfm? fobjectid $=34885$.)

Bertaux, J., et al. (2006), SPICAM on Mars Express: Observing modes and overview of UV spectrometer data and scientific results, J. Geophys. Res., 111, E10S90, doi:10.1029/2006JE002690.

Bougher, S. W., S. Engel, D. P. Hinson, and J. M. Forbes (2001), Mars Global Surveyor Radio Science electron density profiles: Neutral atmosphere implications, Geophys. Res. Lett., 28, 3091-3094.

Bougher, S. W., R. G. Roble, and T. Fuller-Rowell (2002), Simulations of the upper atmospheres of the terrestrial planets, in Atmospheres in the Solar System: Comparative Aeronomy, Geophys. Monogr. Ser., vol. 130, edited by M. Mendillo, A. F. Nagy, and J. H. Waite, pp. 261-288, AGU, Washington, D.C.

Bougher, S. W., S. Engel, D. P. Hinson, and J. R. Murphy (2004), MGS Radio Science electron density profiles: Interannual variability and implications for the martian neutral atmosphere, J. Geophys. Res., 109, E03010, doi:10.1029/2003JE002154.

Bridger, A. F. C., and J. R. Murphy (1998), Mars' surface pressure tides and their behavior during global dust storms, J. Geophys. Res., 103, 8587-8602, doi:10.1029/98JE00242.

Cahoy, K. L., D. P. Hinson, and G. L. Tyler (2006), Radio science measurements of atmospheric refractivity with Mars Global Surveyor, J. Geophys. Res., 111, E05003, doi:10.1029/2005JE002634.

Cahoy, K. L., D. P. Hinson, and G. L. Tyler (2007), Characterization of a semidiurnal eastward-propagating tide at high northern latitudes with Mars Global Surveyor electron density profiles, Geophys. Res. Lett., 34, L15201, doi:10.1029/2007GL030449.

Chamberlain, J. W., and D. M. Hunten (1987), Theory of Planetary Atmospheres, 2nd ed., Academic, New York.

Chapman, S., and R. Lindzen (1970), Atmospheric Tides. Thermal and Gravitational, D. Reidel, Dordrecht, Netherlands.

Clancy, R. T., B. J. Sandor, M. J. Wolff, P. R. Christensen, M. D. Smith, J. C. Pearl, B. J. Conrath, and R. J. Wilson (2000), An intercomparison of ground-based millimeter, MGS TES, and Viking atmospheric temperature measurements: Seasonal and interannual variability of temperatures and dust loading in the global Mars atmosphere, J. Geophys. Res., 105, 9553-9572.

Creasey, J. E., J. M. Forbes, and G. M. Keating (2006), Density variability at scales typical of gravity waves observed in Mars' thermosphere by the MGS accelerometer, Geophys. Res. Lett., 33, L22814, doi:10.1029/ 2006GL027583.

Forbes, J. F. (1995), Tidal and planetary waves, in The Upper Mesosphere and Lower Thermosphere: A Review of Experiment and Theory, edited by R. M. Johnson and T. L. Killeen, pp. 67-87, AGU, Washington, D. C.

Forbes, J. M. (2004), Tides in the middle and upper atmospheres of Mars and Venus, Adv. Space Res., 33, 125-131, doi:10.1016/j.asr.2003. 05.007.

Forbes, J. M., and M. E. Hagan (2000), Diurnal Kelvin wave in the atmosphere of Mars: Towards an understanding of "stationary" density structures observed by the MGS Accelerometer, Geophys. Res. Lett., 27, 3563-3566.

Forbes, J. M., and S. Miyahara (2006), Solar semidiurnal tide in the dusty atmosphere of Mars., J. Atmos. Sci., 63, 1798-1817, doi:10.1175/ JAS3718.1.

Forbes, J. M., A. F. C. Bridger, S. W. Bougher, M. E. Hagan, J. L. Hollingsworth, G. M. Keating, and J. Murphy (2002), Nonmigrating tides in the thermosphere of Mars, J. Geophys. Res., 107(E11), 5113, doi:10.1029/2001JE001582.

Forget, F., F. Montmessin, J. Bertaux, F. González-Galindo, S. Lebonnois, E. Quémerais, A. Reberac, E. Dimarellis, and M. A. López-Valverde (2009), Density and temperatures of the upper Martian atmosphere measured by stellar occultations with Mars Express SPICAM, J. Geophys. Res., 114, E01004, doi:10.1029/2008JE003086.

Hanel, R., et al. (1972), Investigation of the martian environment by infrared spectroscopy on Mariner 9, Icarus, 17, 423-442, doi:10.1016/00191035(72)90009-7.

Heavens, N. G., M. I. Richardson, W. G. Lawson, C. Lee, D. J. McCleese, D. M. Kass, A. Kleinböhl, J. T. Schofield, W. A. Abdou, and J. H. Shirley $(2010)$, Convective instability in the martian middle atmosphere, Icarus, 208, 574-589, doi:10.1016/j.icarus.2010.03.023.

Hess, S. L., R. M. Henry, C. B. Leovy, J. E. Tillman, and J. A. Ryan (1977), Meteorological results from the surface of Mars - Viking 1 and 2, J. Geophys. Res., 82, 4559-4574, doi:10.1029/JS082i028p04559.

Hinson, D. P., R. A. Simpson, J. D. Twicken, G. L. Tyler, and F. M. Flasar (1999), Initial results from radio occultation measurements with Mars Global Surveyor, J. Geophys. Res., 104, 26,997-27,012.

Hinson, D. P., M. Pätzold, R. J. Wilson, B. Häusler, S. Tellmann, and G. L. Tyler (2008), Radio occultation measurements and MGCM simulations of Kelvin waves on Mars, Icarus, 193, 125-138, doi:10.1016/j. icarus.2007.09.009.

Hollingsworth, J. L., and J. R. Barnes (1996), Forced stationary planetary waves in Mars's winter atmosphere., J. Atmos. Sci., 53, 428-448, doi:10.1175/1520-0469(1996)053.

Keating, G. M., et al. (1998), The structure of the upper atmosphere of Mars: In situ accelerometer measurements from Mars Global Surveyor, Science, 279, 1672-1676.

Kieffer, H. H., B. M. Jakosky, and C. W. Snyder (1992), The planet Mars: From antiquity to the present, in Mars, pp. 1-33, edited by H. H. Kieffer et al., Univ. of Ariz. Press, Tucson.

Kleinböhl, A., et al. (2009), Mars Climate Sounder limb profile retrieval of atmospheric temperature, pressure, and dust and water ice opacity, J. Geophys. Res., 114, E10006, doi:10.1029/2009JE003358.

Lee, C., et al. (2009), Thermal tides in the Martian middle atmosphere as seen by the Mars Climate Sounder, J. Geophys. Res., 114, E03005, doi:10.1029/2008JE003285.

Magalhães, J. A., J. T. Schofield, and A. Seiff (1999), Results of the Mars Pathfinder Atmospheric Structure Investigation, J. Geophys. Res., 104, 8943-8956.

Martin, T. Z., A. R. Peterfreund, E. D. Miner, H. H. Kieffer, and G. E. Hunt (1979), Thermal infrared properties of the Martian atmosphere. I - Global behavior at 7, 9, 11, and 20 microns, J. Geophys. Res., 84, 2830-2842, doi:10.1029/JB084iB06p02830.

McCleese, D. J., J. T. Schofield, F. W. Taylor, S. B. Calcutt, M. C. Foote, D. M. Kass, C. B. Leovy, D. A. Paige, P. L. Read, and R. W. Zurek (2007), Mars Climate Sounder: An investigation of thermal and water vapor structure, dust and condensate distributions in the atmosphere, and energy balance of the polar regions, J. Geophys. Res., 112, E05S06, doi:10.1029/2006JE002790.

McDunn, T. L., S. W. Bougher, J. Murphy, M. D. Smith, F. Forget, J. Bertaux, and F. Montmessin (2010), Simulating the density and thermal structure of the middle atmosphere $(80-130 \mathrm{~km})$ of Mars using the MGCM-MTGCM: A comparison with MEX/SPICAM observations, Icarus, 206, 5-17, doi:10.1016/j.icarus.2009.06.034.

Moudden, Y., and J. M. Forbes (2008a), Effects of vertically propagating thermal tides on the mean structure and dynamics of Mars' lower thermosphere, Geophys. Res. Lett., 35, L23805, doi:10.1029/2008GL036086.

Moudden, Y., and J. M. Forbes (2008b), Topographic connections with density waves in Mars' aerobraking regime, J. Geophys. Res., 113, E11009, doi:10.1029/2008JE003107.

Pätzold, M., et al. (2004), MaRS: Mars Express Orbiter Radio Science, in Mars Express: The Scientific Payload, edited by A. Wilson, Eur. Space Agency Spec. Publ., SP-1240, 141-163. (Available at http://sci.esa.int/ science-e/www/object/index.cfm?fobjectid=34885.)

Quémerais, E., J.-L. Bertaux, O. Korablev, E. Dimarellis, C. Cot, B. R. Sandel, and D. Fussen (2006), Stellar occultations observed by SPICAM on Mars Express, J. Geophys. Res., 111, E09S04, doi:10.1029/ 2005JE002604. 
Seiff, A. (1976), The Viking atmosphere structure experiment - Techniques, instruments, and expected accuracies, Space Sci. Instrument., 2, 381-423.

Smith, M. D. (2004), Interannual variability in TES atmospheric observations of Mars during 1999-2003, Icarus, 167, 148-165.

Smith, M. D., J. C. Pearl, B. J. Conrath, and P. R. Christensen (2001), Thermal Emission Spectrometer results: Mars atmospheric thermal structure and aerosol distribution, J. Geophys. Res., 106, 23,929-23,945, doi:10.1029/2000JE001321.

Smith, M. D., M. J. Wolff, N. Spanovich, A. Ghosh, D. Banfield, P. R. Christensen, G. A. Landis, and S. W. Squyres (2006), One Martian year of atmospheric observations using MER Mini-TES, J. Geophys. Res., 111, E12S13, doi:10.1029/2006JE002770.

Tolson, R. H., A. M. Dwyer, J. L. Hanna, G. M. Keating, B. E. George, P. E. Escalera, and M. R. Werner (2005), Application of accelerometer data to Mars Odyssey aerobraking and atmospheric modeling, J. Spacecr. Rockets, 42, 435-443.

Tolson, R. H., E. Bemis, S. Hough, K. Zaleski, G. Keating, J. Shidner, S. Brown, A. Brickler, M. Scher, and P. Thomas (2008), Atmospheric modeling using accelerometer data during Mars Reconnaissance Orbiter aerobraking operations, J. Spacecr. Rockets, 45, 511-518.

Wilson, R. J. (2000), Evidence for diurnal period Kelvin waves in the martian atmosphere from Mars Global Surveyor TES data, Geophys. Res. Lett., 27, 3889-3892.

Wilson, R. J. (2002), Evidence for nonmigrating thermal tides in the Mars upper atmosphere from the Mars Global Surveyor Accelerometer Experiment, Geophys. Res. Lett., 29(7), 1120, doi:10.1029/2001GL013975.

Wilson, R. J., and K. Hamilton (1996), Comprehensive model simulation of thermal tides in the Martian atmosphere, J. Atmos. Sci., 43, 1290-1326.
Withers, P. (2003), Tides in the Martian atmosphere - and other topics, Ph.D. thesis, Univ. of Ariz., Tucson.

Withers, P. (2006), Mars Global Surveyor and Mars Odyssey Accelerometer observations of the martian upper atmosphere during aerobraking, Geophys. Res. Lett., 33, L02201, doi:10.1029/2005GL024447.

Withers, P., S. W. Bougher, and G. M. Keating (2003), The effects of topographically-controlled thermal tides in the martian upper atmosphere as seen by the MGS accelerometer, Icarus, 164, 14-32.

Zurek, R. W. (1976), Diurnal tide in the martian atmosphere, J. Atmos. Sci., $33,321-337$.

Zurek, R. W. (1988), Free and forced modes in the Martian atmosphere, J. Geophys. Res., 93, 9452-9462, doi:10.1029/JD093iD08p09452.

Zurek, R. W. (1992), Comparative aspects of the climate of Mars: An introduction to the current atmosphere, in Mars, edited by H. H. Kieffer et al., pp. 799-817, Univ. of Ariz. Press, Tucson.

Zurek, R. W., and C. B. Leovy (1981), Thermal tides in the dusty martian atmosphere - A verification of theory, Science, 213, 437-439, doi:10.1126/science.213.4506.437.

Zurek, R. W., J. R. Barnes, R. M. Haberle, J. B. Pollack, J. E. Tillman, and C. B. Leovy (1992), Dynamics of the atmosphere of Mars, in Mars, edited by H. H. Kieffer et al., pp. 835-933, Univ. of Ariz. Press, Tucson.

J.-L. Bertaux and F. Montmessin, Service d'Aéronomie du CNRS, BP3, F-91371, Verrières-le-Buisson, France.

R. Pratt and P. Withers, Astronomy Department, Boston University, 725 Commonwealth Ave., Boston, MA 02215, USA. (withers@bu.edu) 